\title{
Evaluation of exposures and respiratory health at a coffee roasting, flavoring, and packaging facility.
}

Brie Hawley, MS, PhD Laura E. Reynolds, MPH, BSN, RN R. Reid Harvey, DVM, MPH Stephen B. Martin, Jr., PhD, PE

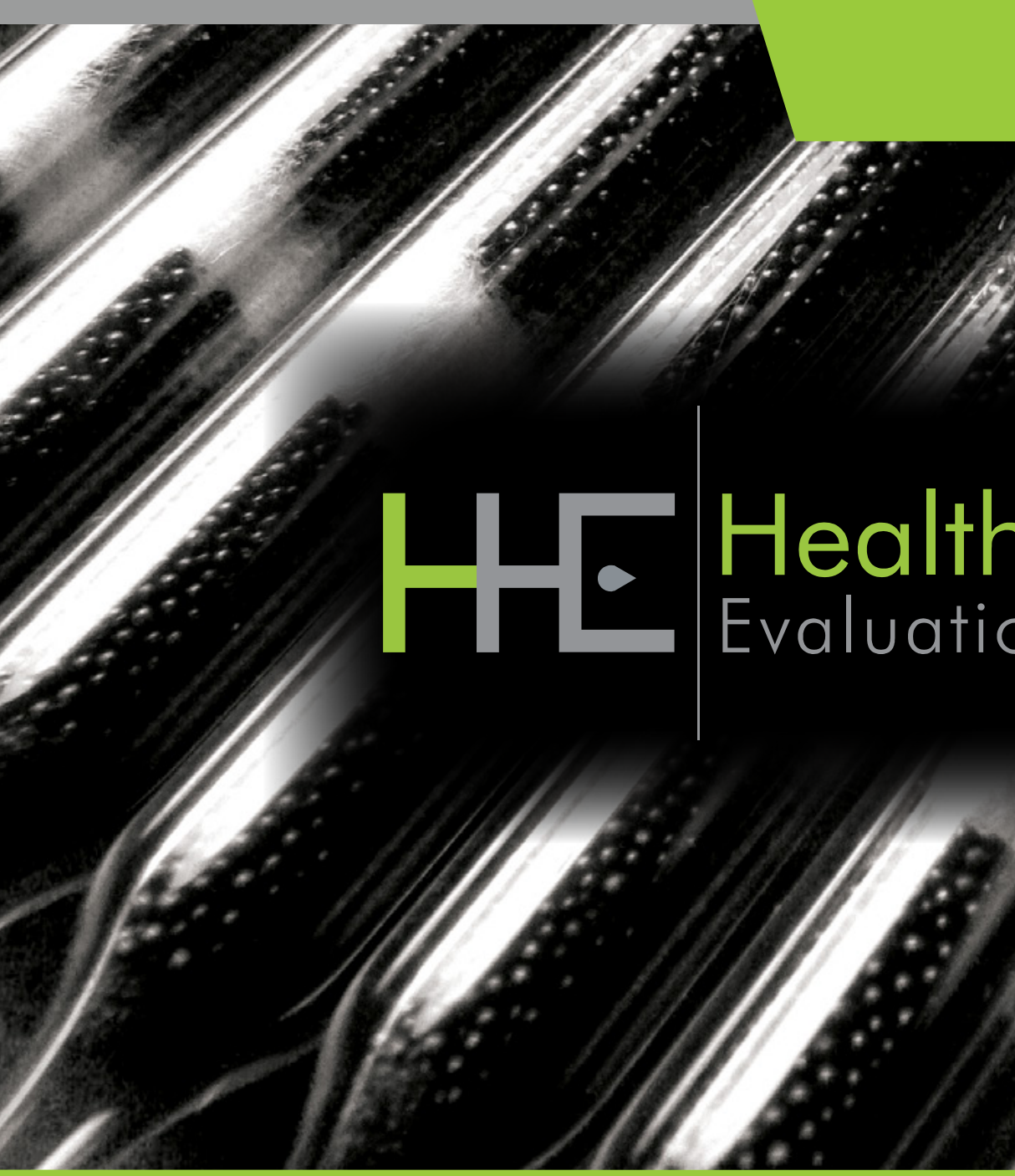

Report No. 2017-0054-3327

September 2018

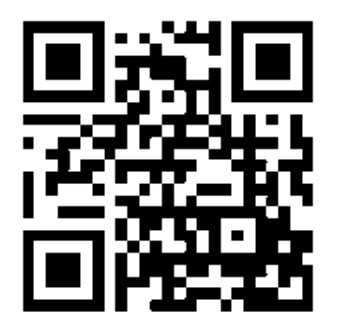

U.S. Department of Health and Human Services Centers for Disease Control and Prevention

National Institute for Occupational Safety and Health






\section{Contents}

Highlights. i

Abbreviations vi

Summary 1

Introduction .......................................... 2

Background........................................... 2

Process Description ................................ 6

Methods ............................................. 8

Results ................................................ 13

Discussion ........................................... 19

Conclusions ........................................... 26

Recommendations............................ 27

Appendix A:Tables ............................ 32

References.......................................... 44

Acknowledgements.......................... 53

The employer is required to post a copy of this report for 30 days at or near the workplace(s) of affected employees. The employer must take steps to ensure that the posted report is not altered, defaced, or covered by other material.

The cover photo is a close-up image of sorbent tubes, which are used by the HHE Program to measure airborne exposures. This photo is an artistic representation that may not be related to this Health Hazard Evaluation. 


\section{Highlights of this Evaluation}

The Health Hazard Evaluation Program of the National Institute for Occupational Safety and Health received a request from management at a coffee roasting, flavoring, and packaging facility regarding concerns about potential health effects from exposure to diacetyl during coffee roasting, grinding, and flavoring.

\section{What We Did}

- We visited the coffee roasting, flavoring, and packaging facility on August 23-25, 2017 and August 28-30, 2017.

- We collected full-shift (hours), task (minutes), and instantaneous (seconds) air samples to measure concentrations of diacetyl, 2,3-pentanedione, and 2,3-hexanedione over multiple days.

- We collected samples of liquid flavorings to measure their emission potential for diacetyl, 2,3-pentanedione, and 2,3-hexanedione.

- We measured real-time air levels of carbon monoxide and carbon dioxide.

- We assessed the ventilation system at the facility.

- We administered a health questionnaire to employees and performed medical tests.

\section{What We Found}

- During personal full-shift sampling, some employees (flavoring room attendant, grinder operator, roaster operators, and packaging operators, and employees with duties in the production and administrative areas) were exposed to diacetyl at concentrations above the recommended exposure limit of 5 parts per billion ( $\mathrm{ppb}$ ). The highest measured concentration of $47.3 \mathrm{ppb}$ was measured on a grinder operator.

We evaluated the respiratory health and airborne exposures to the alphadiketones diacetyl, 2,3-pentanedione, and 2,3-hexanedione, other volatile organic compounds, carbon monoxide, and carbon dioxide among employees at a coffee roasting, flavoring, and packaging facility. Some employees in the production area of the facility had personal full-shift exposures that exceeded the NIOSH recommended exposure limit for diacetyl and 2,3-pentanedione. In addition, personal air sampling during short-term tasks identified several tasks (e.g., flavoring coffee, grinding coffee beans, packaging coffee, cleaning the flavoring mixer, and cleaning the grinders) with higher exposures to alpha-diketones than other tasks. Air levels of carbon monoxide measured on employees that ground or flavored ground beans exceeded the NIOSH ceiling limit of 200 parts per million. Air levels of carbon monoxide near the packaging grinders exceeded 200 parts per million. Eye and nose symptoms were the most commonly reported symptoms. Wheezing, shortness of breath, and breathing trouble were the most common lower respiratory symptoms reported. More than four times as many employees as expected reported asthma than in the U.S. population with a similar demographic distribution. Four (13\%) of 30 participants had abnormal spirometry. We recommend installing local exhaust and implementing other ventilation changes, modification of work practices, training employees about workplace hazards, and respirator use. We also recommend instituting a medical monitoring program. 
- During personal full-shift samples, some employees (flavoring room attendant, grinder operator, packaging operators, and employees with duties in the production areas) were exposed to 2,3-pentanedione concentrations above the recommended exposure limit of $9.3 \mathrm{ppb}$. The highest measured full-shift concentration of $177.9 \mathrm{ppb}$ 2,3-pentanedione was measured on a flavoring attendant.

- Employees wore half-face or full-face respirators equipped with organic vapor cartridges while flavoring or grinding coffee in the flavoring room and roast room, respectively.

- Levels of diacetyl and 2,3-pentanedione in the air during personal short-term sampling were higher for tasks involving flavoring coffee (maximum $36.2 \mathrm{ppb}$ diacetyl and $723.5 \mathrm{ppb} 2,3$-pentanedione), grinding roasted beans (maximum 245.9 ppb diacetyl and 228.4 ppb 2,3-pentanedione ppb), and packaging roasted coffee (maximum $38.1 \mathrm{ppb}$ diacetyl and $68.0 \mathrm{ppb}$ 2,3-pentanedione).

- Instantaneous canister samples collected while employees flavored roasted coffee were as high as $42.0 \mathrm{ppb}$ for diacetyl and $211.0 \mathrm{ppb}$ for 2,3-pentanedione. Instantaneous samples collected while an employee ground unflavored coffee were as high as $51.6 \mathrm{ppb}$ for diacetyl and $49.2 \mathrm{ppb}$ for 2,3-pentanedione.

- Air levels of carbon monoxide measured on employees that ground coffee or flavored ground coffee exceeded the NIOSH ceiling limit of 200 parts per million.

- Some bulk samples of liquid flavorings emitted diacetyl, and/or 2,3-pentanedione.

- Eye and nose symptoms were the most commonly reported symptoms. Some employees reported their symptoms were caused or aggravated by green bean coffee burlap bags, dust, flavorings, grinding coffee, or packaging coffee.

- Wheezing or whistling in the chest, breathing trouble, and shortness of breath were the most commonly reported lower respiratory symptoms.

- More than four times as many employees reported current physician-diagnosed asthma than expected.

- Almost three times as many employees reported having phlegm for three consecutive months than expected.

- Four (13\%) of 30 participants had abnormal spirometry.

- Two (6\%) of 31 participants had high exhaled nitric oxide, a marker of allergic airways inflammation.

\section{What the Employer Can Do}

- Ensure employees understand potential hazards (e.g., diacetyl, 2,3-pentanedione, carbon monoxide, carbon dioxide, green and roasted coffee dust) in the workplace and how to protect themselves.

- Keep all doors between the production and non-production areas closed at all times. 
- Limit the amount of time non-production employees spend in the production area.

- Install local exhaust ventilation at the large grinder, grinder in the flavoring room, packaging grinders, and flavoring mixers to reduce air concentrations of alphadiketones (diacetyl and 2,3-pentanedione) and carbon monoxide during grinding of coffee.

- Install a carbon monoxide monitor near the large grinder, grinder in the flavoring room, and the packaging grinders to alert employees if carbon monoxide levels exceed the National Institute for Occupational Safety and Health ceiling limit of $200 \mathrm{ppm}$.

- Work with a ventilation engineer to ensure the administrative areas and breakroom are maintained under positive pressure compared with the production spaces.

- Ensure hoppers filled with whole bean and ground coffee are covered to minimize the off-gassing of alpha-diketones and carbon monoxide into the production space.

- Automate transfer of roasted beans, whenever possible, to minimize manual handling.

- Minimize production tasks that require employees to place their heads inside or near roasted bean bins.

- Conduct follow-up air sampling to verify that the modifications have been effective in reducing exposures of diacetyl, 2,3-pentanedione, and carbon monoxide to below the recommended exposure limits.

- Consider additional engineering controls if follow-up air sampling demonstrates that exposures remain above the recommended exposure limits.

- Until exposures are controlled, provide respiratory protection to be used during tasks with elevated exposures, specifically during flavoring and grinding coffee, including flavoring and grinding in the packaging areas.

- Make N95 disposable filtering-face piece respirators available for voluntary use for protection against dust exposure when emptying burlap bags of green beans, cleaning the exhaust system of chaff, emptying the chaff containers, or cleaning the green bean storage area.

- Encourage employees to report new, worsening, or ongoing respiratory symptoms to their personal healthcare providers and to a designated individual at the workplace.

- Institute a medical monitoring program for employees who work in the production area.

\section{What Employees Can Do}

- Use any local exhaust ventilation as instructed by your employer after it is installed.

- As much as possible, avoid placing your head directly above or inside roasted whole bean or ground coffee storage bins.

- Some employees may wish to use N95 disposable filtering-facepiece respirators when emptying burlap bags of green beans, when cleaning the exhaust system of chaff, when emptying the chaff containers, or when cleaning the green bean storage area. 
- Report new, persistent, or worsening respiratory symptoms to your personal healthcare provider(s) and, as instructed, to a designated individual at your workplace.

- Participate in any personal air sampling offered by your employer.

- Participate in your employer's medical monitoring program as instructed by your employer. 
This page left intentionally blank 


\section{Abbreviations}

\begin{tabular}{|c|c|}
\hline$\mu \mathrm{m}$ & Micrometer \\
\hline$\mu g$ & Microgram \\
\hline${ }^{\circ} \mathrm{F}$ & degrees Fahrenheit \\
\hline ACGIH® & American Conference of Governmental Industrial Hygienists \\
\hline $\mathrm{APF}$ & Assigned protection factor \\
\hline $\mathrm{AX}$ & Area of reactance \\
\hline CFR & Code of Federal Regulations \\
\hline $\mathrm{CI}$ & Confidence interval \\
\hline $\mathrm{CO}$ & Carbon monoxide \\
\hline $\mathrm{CO}_{2}$ & Carbon dioxide \\
\hline COPD & Chronic obstructive pulmonary disease \\
\hline DR5-R20 & The difference between resistance at 5 and 20 Hertz \\
\hline EF-1 & Upblast centrifugal exhaust fan \\
\hline $\mathrm{FEV}_{1}$ & 1-second forced expiratory volume \\
\hline Fres & Resonant frequency \\
\hline FVC & Forced vital capacity \\
\hline GERD & Gastroesophageal reflux disease \\
\hline $\mathrm{Hz}$ & Hertz \\
\hline $\mathrm{kPa} /(\mathrm{L} / \mathrm{s})$ & Kilopascals per liter per second \\
\hline IDLH & Immediately dangerous to life or health \\
\hline LPM & Liters per minute \\
\hline LOD & Limit of detection \\
\hline LOQ & Limit of quantitation \\
\hline $\mathrm{mg} / \mathrm{m}^{3}$ & Milligrams per cubic meter of air \\
\hline $\mathrm{mL}$ & Milliliter \\
\hline $\mathrm{mL} / \mathrm{min}$ & Milliliter per minute \\
\hline MAHU & Make-up air-handling unit \\
\hline NHANES & National Health and Nutrition Examination Survey \\
\hline NIOSH & National Institute for Occupational Safety and Health \\
\hline OEL & Occupational exposure limit \\
\hline OSHA & Occupational Safety and Health Administration \\
\hline PEL & Permissible exposure limit \\
\hline $\mathrm{ppb}$ & Parts per billion \\
\hline ppm & Parts per million \\
\hline QC & Quality control \\
\hline R5 & Resistance at 5 Hertz \\
\hline
\end{tabular}


R20

Resistance at 20 Hertz

REL

Recommended exposure limit

SMR

Standardized morbidity ratios

$\mathrm{RH}$

Relative humidity

STEL

Short-term exposure limit

TLV®

Threshold limit value

TWA

Time-weighted average

VOC

Volatile organic compound

$\mathrm{X} 5$

Reactance at 5 Hertz 


\section{Summary}

In February 2017, the Health Hazard Evaluation Program of the National Institute for Occupational Safety and Health received a request from management at a coffee roasting, flavoring, and packaging facility regarding concerns about potential health effects from exposure to diacetyl and 2,3-pentanedione during coffee roasting, grinding, and flavoring. In August 2017, we conducted an industrial hygiene survey and ventilation assessment at the facility. The industrial hygiene survey consisted of the collection of air samples and bulk samples of coffee for the analysis of diacetyl, 2,3-pentanedione, and 2,3-hexanedione. We used continuous monitoring instruments to monitor total volatile organic compounds, carbon monoxide, carbon dioxide, temperature, and relative humidity in specific areas and during tasks. We also conducted a medical evaluation of employees that consisted of a health questionnaire and breathing tests.

Forty-nine of the 51 full-shift personal samples collected during the industrial hygiene survey exceeded the NIOSH recommended exposure limit for diacetyl of 5 parts per billion, with a maximum concentration of 47.3 parts per billion. Thirty-six of the 51 fullshift samples exceeded the NIOSH recommended exposure limit for 2,3-pentanedione of 9.3 parts per billion, with a maximum of 177.9 parts per billion. We identified work tasks that resulted in relatively higher air concentrations of diacetyl and 2,3-pentanedione than other tasks. Specifically, grinding roasted coffee beans, flavoring roasted beans, cleaning the flavoring mixer, cleaning the grinder, and packaging coffee were associated with higher diacetyl and 2,3-pentanedione levels. We observed high instantaneous levels of diacetyl and 2,3-pentanedione during grinding of coffee, weighing of flavorings, flavoring coffee, and packaging ground coffee. Air levels of carbon monoxide collected on employees with duties that included grinding unflavored and flavored roasted beans exceeded the NIOSH ceiling limit of 200 parts per million. Carbon monoxide levels in the area near the packaging grinders also exceeded 200 parts per million. Carbon dioxide levels were low throughout most of the facility.

Overall, the most commonly reported symptoms were associated with mucous membranes, specifically the eyes and nose. Some production employees reported their symptoms were caused or aggravated by green bean coffee burlap bags, dust, flavorings, grinding coffee, or packaging coffee. Wheezing or whistling in the chest, breathing trouble, and shortness of breath were the most commonly reported lower respiratory symptoms. Participants reporting a current asthma diagnosis or ever having a diagnosis of asthma were 4.1 and 3.1 times higher, respectively, compared with the U.S. population of the same age, race/ethnicity, sex, and cigarette smoking distribution. Participants also reported phlegm for three consecutive months 2.5 times more than expected compared with the U.S. population. Four (13\%) of 30 participants had abnormal spirometry; two $(6 \%)$ of 31 participants had high exhaled nitric oxide, a marker of allergic airways inflammation. We recommend implementing local exhaust and other ventilation changes, modification of work practices, training employees about workplace hazards, and respirator use. We also recommend instituting a medical monitoring program to identify any employees who may be developing work-related lung disease (e.g., asthma, obliterative bronchiolitis) and to help management prioritize interventions to prevent occupational lung disease. 


\section{Introduction}

In February 2017, the National Institute for Occupational Safety and Health (NIOSH) received a management request for a health hazard evaluation at a coffee roasting, flavoring, and packaging facility regarding potential worker exposure to diacetyl during coffee processing. In August 2017, we conducted an industrial hygiene survey and ventilation assessment at the facility. We collected area and personal breathing zone air samples for volatile organic compounds (VOCs), including diacetyl, 2,3-pentanedione, and 2,3-hexanedione. We also monitored and recorded carbon monoxide (CO), carbon dioxide $\left(\mathrm{CO}_{2}\right)$, and total VOCs. We also conducted a medical survey.

\section{Background}

Previous Industrial Hygiene Sampling at This Coffee Roasting, Flavoring, and Packaging Facility

The state Occupational Safety and Health Administration (OSHA) program conducted an industrial hygiene investigation at this facility in November and December 2015 to determine compliance with state OSHA regulations. The site visit was initiated because the employer was selected as part of state OSHA's target health program. Measurements of CO, noise levels, and diacetyl were collected by the state OSHA and shared with the employer. Results from the state OSHA industrial hygiene survey prompted management to submit a health hazard evaluation request.

\section{Diacetyl and 2,3-Pentanedione}

Diacetyl (2,3-butanedione) and 2,3-pentanedione are VOCs known as alpha-diketones that are added as ingredients in food flavorings used in some food products such as microwave popcorn, bakery mixes, and flavored coffee [Day et al. 2011; Kanwal et al. 2006; Bailey et al. 2015]. Diacetyl, 2,3-pentanedione, other VOCs, and gases such as $\mathrm{CO}$ and $\mathrm{CO}_{2}$ are naturally produced and released during the coffee roasting process [Duling et al. 2016; Raffel and Thompson 2013; Daglia et al. 2007; Nishimura et al. 2003; Newton 2002]. Grinding roasted coffee beans produces a greater surface area for off-gassing (sometimes called degassing) of these compounds [Akiyama et al. 2003]. Often, coffee roasting facilities package newly roasted coffee in permeable bags or in bags fitted with one-way valves to allow the coffee to off-gas after it is packaged. Sometimes, newly roasted coffee is placed in bins or containers and allowed to off-gas before packaging.

NIOSH has recommended exposure limits (RELs) for diacetyl and 2,3-pentanedione in workplace air (Table 1) [NIOSH 2016]. The NIOSH objective in establishing RELs for diacetyl and 2,3-pentanedione is to reduce the risk of respiratory impairment (decreased lung function) and the severe irreversible lung disease obliterative bronchiolitis associated with occupational exposure to these chemicals. NIOSH RELs are intended to protect workers exposed to diacetyl or 2,3-pentanedione for a 45-year working lifetime. The REL for diacetyl is based on a quantitative risk assessment which necessarily contains assumptions and some uncertainty. Analytical limitations current at the time were taken into consideration in setting 
the REL for 2,3-pentanedione. The RELs should be used as a guideline to indicate when steps should be taken to reduce exposures in the workplace.

These exposure limits and the accompanying recommendations for control of exposures were derived from a risk assessment of flavoring-exposed workers. At an exposure equal to the diacetyl REL, the risk of adverse health effects is low. NIOSH estimated about 1 in 1,000 workers exposed to diacetyl levels of 5 parts per billion ( $\mathrm{ppb}$ ) as a time-weighted average (TWA) for 8 hours a day, 40 hours a week for a 45-year working lifetime would develop reduced lung function (defined as forced expiratory volume in one second $\left[\mathrm{FEV}_{1}\right]$ below the lower limit of normal) as a result of that exposure. NIOSH predicted that around 1 in 10,000 workers exposed to diacetyl at $5 \mathrm{ppb}$ for a 45-year working lifetime would develop more severe lung function reduction $\left(\mathrm{FEV}_{1}\right.$ below $60 \%$ predicted, defined as moderately severe by the American Thoracic Society [Pellegrino et al. 2005]). Workers exposed for less time would be at lower risk for adverse lung effects.

\section{2,3-Hexanedione}

2,3-Hexanedione is also an alpha-diketone sometimes used as a substitute for diacetyl and is produced naturally during coffee roasting. In a study using animals, there was some evidence that 2,3-hexanedione might also damage the lungs, but it appeared to be less toxic than diacetyl and 2,3-pentanedione [Morgan et al. 2016]. There are no established occupational exposure limits for 2,3-hexanedione.

Carbon Monoxide (CO) and Carbon Dioxide $\left(\mathrm{CO}_{2}\right)$

$\mathrm{CO}$ and $\mathrm{CO}_{2}$ are gases produced by combustion. They are also produced as a result of reactions that take place during coffee roasting. These gases are released during and after roasting and grinding by a process called off-gassing [Anderson et al. 2003; Hawley 2017]. High exposures to $\mathrm{CO}$ and $\mathrm{CO}_{2}$ can cause headache, dizziness, fatigue, nausea, altered mentation, rapid breathing, impaired consciousness, coma, and death [Newton 2002; Nishimura et al. 2003; Langford 2005; CDC 2013a; Raffel and Thompson 2013; Rose et al. 2017]. Occupational exposure limits for $\mathrm{CO}$ and $\mathrm{CO}_{2}$ are listed in Table 1.

\section{Exposure Limits}

We utilize mandatory (legally enforceable) and recommended occupational exposure limits (OELs) when evaluating workplace hazards. OELs have been developed by federal agencies and safety and health organizations to prevent adverse health effects from workplace exposures.

\section{Occupational Safety and Health Administration (OSHA) [Mandatory]}

The U.S. Department of Labor's OSHA permissible exposure limits (PELs) are legal limits that are enforceable in workplaces covered under the Occupational Safety and Health Act. OSHA PELs represent the legal maximum for a TWA exposure to a physical or chemical agent over a work shift [OSHA 2018]. OSHA short-term exposure limits (STELs) are the legal maximum average exposure for a 15-minute time period. Some chemicals also have an OSHA ceiling value which represent levels that must not be exceeded at any time. Currently, there are no PELs for diacetyl, 2,3-pentanedione, or 2,3-hexanedione. For substances for 
which an OSHA PEL has not been issued, violation of the OSHA General Duty Clause can be considered using available occupational exposure references and recommendations [OSHA 1993; OSHA 2003], such as the American Conference of Governmental Industrial Hygienists $\left(\mathrm{ACGIH}^{\circledR}\right)$ Threshold Limit Values $\left(\mathrm{TLVs}^{\circledR}\right)$ and NIOSH RELs.

American Conference of Governmental Industrial Hygienist (ACGIH ${ }^{\mathbb{R}}$ ) [Recommendations] $\mathrm{ACGIH}^{\circledR}$ is a professional, not-for-profit scientific association that reviews existing published, peer-reviewed scientific literature and publishes recommendations for levels of substances in air based on an 8-hour workday and 40-hour workweek. These recommendations are called threshold limit values (TLVs ${ }^{\circledR}$ ) [ACGIH 2018a]. ACGIH ${ }^{\circledR}$ TLVs $^{\circledR}$ are not standards; they are health-based guidelines derived from scientific and toxicological information. ACGIH ${ }^{\circledR}$ provides TLV $^{\circledR}$-TWA guidelines that are levels that should not be exceeded during any 8-hour workday of a 40-hour workweek. ACGIH ${ }^{\circledR}$ also provides TLV $^{\circledR}$ STEL guidelines which are 15-minute exposure levels that should not be exceeded during a workday. Exposures above the TLV ${ }^{\circledR}$-TWA but less than the TLV ${ }^{\circledR}$-STEL should be (1) less than 15 minutes, (2) occur no more than four times a day, and (3) be at least 60 minutes between exposures [ACGIH ${ }^{\circledR}$ 2018a]. Additionally, ACGIH ${ }^{\circledR}$ provides TLV $^{\circledR}$-Ceiling values which are levels that should not be exceeded at any time during a work shift. The $\mathrm{ACGIH}^{\circledR}$ $\mathrm{TLV}^{\circledR}$-TWA for diacetyl is $10 \mathrm{ppb}$. The TLV ${ }^{\circledR}-\mathrm{STEL}$ for diacetyl is $20 \mathrm{ppb}$. Currently, there is no $\mathrm{TLV}^{\circledR}$-TWA or TLV ${ }^{\circledR}$-STEL for 2,3-pentanedione. ACGIH ${ }^{\circledR}$ has placed 2,3-pentanedione on the 2017 list of Chemical Substances and Other Issues Under Study [ACGIH ${ }^{\circledR} 2018 \mathrm{~b}$ ].

National Institute for Occupational Safety and Health (NIOSH) [Recommendations] NIOSH provides RELs as TWA concentrations that should not be exceeded over an 8 or 10-hour work shift, during a 40-hour workweek [NIOSH 2010]. RELs are intended to be protective over a 45-year working lifetime. NIOSH also provides STELs which are 15-minute TWA exposures that should not be exceeded at any time during a workday [NIOSH 2016]. Some chemicals have ceiling values which are concentrations that should not be exceeded at any time [NIOSH 2016]. For some chemicals, NIOSH has established an Immediately Dangerous to Life or Health (IDLH) value. An IDLH value is a concentration of an air contaminant that can cause death or immediate or delayed permanent adverse health effects, or prevent escape from such an environment. Currently, NIOSH has RELs and STELs for diacetyl and 2,3-pentanedione. NIOSH does not have a REL or a STEL for 2,3-hexanedione. NIOSH does not have ceiling limits or IDLH values for diacetyl, 2,3-pentanedione, or 2,3-hexanedione.

For diacetyl and 2,3-pentanedione, the NIOSH RELs are $5.0 \mathrm{ppb}$ and $9.3 \mathrm{ppb}$, respectively, as a TWA for up to an 8-hour workday during a 40-hour workweek (Table 1). The NIOSH STELs are $25 \mathrm{ppb}$ for diacetyl and $31 \mathrm{ppb}$ for 2,3-pentanedione [NIOSH 2016]. The NIOSH exposure limits do not differentiate between natural and synthetic chemical origin of diacetyl or 2,3-pentanedione. Although the NIOSH exposure limit for 2,3-pentanedione is above that of diacetyl, 2,3-pentanedione has been shown to be as hazardous as diacetyl [Hubbs et al. 2012; Morgan et al. 2012]. The hazard potential probably increases when these chemicals occur in combination with each other; having exposure to chemicals with the same functional alpha-diketone group and effect on the same system or organ (e.g., lungs) can result in 
additive effects [ACGIH 2017a]. The NIOSH REL is higher for 2,3-pentanedione than for diacetyl largely because analytic measures were not available in a validated OSHA method to detect 2,3-pentanedione at lower levels. In addition to the REL, NIOSH also recommends an action level for diacetyl of $2.6 \mathrm{ppb}$ to be used with exposure monitoring in an effort to ensure employee exposures are routinely below the diacetyl REL. When exposures exceed the action level, employers should take corrective action (i.e., determine the source of exposure, identify methods for controlling exposure) to ensure that exposures are maintained below the NIOSH REL for diacetyl [NIOSH 2016].

Table 1. Exposure limits for compounds sampled during the NIOSH survey, August 2017

\begin{tabular}{|c|c|c|c|c|c|c|}
\hline \multirow{2}{*}{ Compound } & OSHA* & \multicolumn{2}{|c|}{ ACGIH } & \multicolumn{3}{c|}{ NIOSH } \\
\cline { 2 - 7 } & PEL & TLV & STEL & REL & STEL & IDLH \\
\hline Diacetyl & - & $10 \mathrm{ppb}$ & $20 \mathrm{ppb}$ & $5 \mathrm{ppb} \dagger$ & $25 \mathrm{ppb}$ & - \\
\hline 2,3-Pentanedione & - & - & - & $9.3 \mathrm{ppb} \dagger$ & $31 \mathrm{ppb}$ & - \\
\hline 2,3-Hexanedione & - & - & - & - & - & - \\
\hline Carbon dioxide + & $5,000 \mathrm{ppm}$ & $5,000 \mathrm{ppm}$ & $30,000 \mathrm{ppm}$ & $5,000 \mathrm{ppm}$ & $30,000 \mathrm{ppm}$ & $40,000 \mathrm{ppm}$ \\
\hline Carbon monoxide $\ddagger$ & $50 \mathrm{ppm}$ & $25 \mathrm{ppm}$ & - & $35 \mathrm{ppm}$ & $\begin{array}{c}200 \mathrm{ppm} \\
\text { (ceiling limit)§ }\end{array}$ & $1,200 \mathrm{ppm}$ \\
\hline
\end{tabular}

Note: OSHA=Occupational Safety and Health Administration; ACGIH=American Conference of Governmental Industrial Hygienists; NIOSH=National Institute for Occupational Safety and Health; $P E L=$ permissible exposure limit; $S T E L=$ short-term exposure limit; $T L V=$ threshold limit value; $R E L=$ recommended exposure limit; IDLH=immediately dangerous to life or health; $p p b=$ parts per billion; ppm=parts per million; "“_"=no exposure limit available.

*There are no OSHA STEL values for the compounds in the table.

$\dagger$ The NIOSH RELs for diacetyl and 2,3-pentanedione are time-weighted averages for up to an 8-hour day, during a 40-hour workweek.

$\$ O S H A$ and NIOSH limits are designed for occupational exposure measurements in manufacturing and other trades that have potential sources of carbon dioxide or carbon monoxide (e.g., coffee roasting, welding, vehicle exhaust, diesel engine exhaust). Typical levels of carbon monoxide in offices are 0-5 ppm. In office settings, carbon dioxide generally should not be greater than $700 \mathrm{ppm}$ above outdoor carbon dioxide levels; this typically corresponds to indoor concentrations below $1200 \mathrm{ppm}$.

§This is the NIOSH ceiling exposure limit for carbon monoxide. A ceiling concentration should not be exceeded at any time.

\section{Obliterative Bronchiolitis}

Obliterative bronchiolitis is a serious, often disabling, lung disease that involves scarring of the very small airways (i.e., bronchioles). Symptoms of this disease may include cough, shortness of breath on exertion, and/or wheeze, that do not typically improve away from work [NIOSH 2012]. Occupational obliterative bronchiolitis has been identified in flavoring manufacturing workers and microwave popcorn workers who worked with flavoring chemicals or butter flavorings [Kreiss 2013; Kim et al. 2010; Kanwal et al. 2006]. Obliterative bronchiolitis has also been identified in employees at a coffee roasting and packaging facility that produced unflavored and flavored coffee [CDC 2013b]. A NIOSH health hazard evaluation at that facility found diacetyl and 2,3-pentanedione concentrations in the air that were elevated (range: $4.3 \mathrm{ppb}$ to $166 \mathrm{ppb}$ diacetyl; $<5.2 \mathrm{ppb}$ to $199 \mathrm{ppb}$ 2,3-pentanedione) and identified three sources: 1) flavoring chemicals added to roasted coffee beans in the flavoring area; 2) grinding unflavored roasted coffee beans and packaging unflavored ground and whole bean roasted coffee in a distinct area of the facility, and 3) storing roasted coffee in hoppers for off-gassing, on a mezzanine above the grinding/ 
packaging process [Duling et al. 2016]. At the time of the previous health hazard evaluation, workers had excess shortness of breath and obstruction on spirometry, both consistent with undiagnosed lung disease. Respiratory illness was associated with exposure and not limited to the flavoring areas [Bailey et al. 2015]. However, all workers who were diagnosed with obliterative bronchiolitis had worked in the flavoring area. To date, no cases of obliterative bronchiolitis have been reported in workers at coffee roasting and packaging facilities that produce only unflavored coffee.

\section{Work-related Asthma}

Work-related asthma refers to asthma that is brought on by ("occupational asthma") or made worse by ("work-exacerbated asthma" or "work-aggravated asthma") workplace exposures [Tarlo 2016; Tarlo and Lemiere 2014; OSHA 2014; Henneberger et al. 2011]. It includes asthma due to sensitizers, which cause disease through immune (allergic) mechanisms, and asthma due to irritants, which cause disease through non-immune mechanisms. Symptoms of work-related asthma include episodic shortness of breath, cough, wheeze, and chest tightness. The symptoms may begin early in a work shift, towards the end of a shift, or hours after a shift. They generally, but do not always, improve or remit during periods away from work, such as on weekends or holidays.

Green and roasted coffee dust and castor beans (from cross-contamination of bags used to transport coffee) are known risk factors for occupational asthma [Figley and Rawling 1950; Karr et al. 1978; Zuskin et al. 1979, 1985; Thomas et al. 1991]. Persons who become sensitized (develop an immune reaction) to coffee dust can subsequently react to relatively low concentrations in the air. Others may experience irritant-type symptoms from exposure to coffee dust [Oldenburg et al. 2009].

\section{Process Description}

In August 2017 the coffee roasting and packaging facility employed approximately 54 total employees, with approximately 48 of those employees in production. The employees were not represented by a union. The facility had been at this location since 2000 . The production area was approximately 22,125 square feet in size with the roast room being approximately 6,000 square feet. An average of 10,640 pounds of coffee was roasted and packaged per day, and approximately $65 \%$ of the coffee produced was ground coffee. The facility received and stored a one month supply of green coffee, or approximately 250,000 pounds on site. Green beans were stored in burlap bags in a designated green bean storage area.

To prepare a batch for roasting, a roaster operator weighed the desired amount of green beans before adding them to the roaster. Two roasters were operating during our visit. The small roaster could hold 90 kilogram or approximately 198 pounds of green coffee beans, and the large roaster could hold up to 250 kilogram or approximately 550 pounds of green coffee beans. When ready, the roaster operator dropped the green beans into the roaster. The beans were heated to a specific temperature and for a specific time period for the desired roast. Time and temperature varied among types of roasts. On average, roasts lasted 11 minutes to 
20 minutes. Occasionally, the roaster operator would pull a small sample of beans from the roaster to check the color of the beans. At the end of each cycle, the roaster operator emptied the roasted beans into a cooling bin where they were agitated by a rotating arm. The cooling bins at both of the roasters utilized a downdraft exhaust system that pulled air downward past the roasted beans to accelerate cooling. The downdraft systems pulled room air down through the roaster and then out of the building through a ventilation duct and roof exhaust. The roaster operator monitored the roasting equipment throughout the roasting and cooling process. After cooling, the roasted beans were dispensed from the cooling bin by a pneumatic siphon system through a destoner and then dispensed into a large rolling hopper. The roaster operator then manually moved the rolling hoppers to a storage area until needed for further processing, including grinding, flavoring, and packaging. The roasters were routinely cleaned to remove accumulated chaff from the exhaust lines. A quality control (QC) technician periodically brewed roasted coffee in a separate quality control room to assess product quality and taste.

Roasted whole bean coffee was transported by the flavoring room attendant into the flavoring room using a bin on wheels. In the flavoring room, the flavoring attendant would scoop roasted beans into one of two open barrels mounted on a rotating rack. The attendant would weigh liquid flavorings using a small scale and pour the liquid flavorings into the rotating barrel of roasted coffee beans. After mixing, the attendant would manually empty the beans into storage bins until needed for further processing, including packaging or grinding. Whole bean flavored coffee would either be sent to the packaging area for packaging, or ground using a grinder in the flavoring room. For grinding flavored coffee, the attendant would use the grinder in the flavoring room to grind approximately 40 pounds of coffee at a time. Ground flavored coffee was dispensed and stored in closed storage bins until further processing in the packaging area.

In the packaging area, orders were completed using packaging lines that included 1) the TME line that packaged individual serving pods of coffee ground in the machine; 2) the Rossi line that packaged individual serving pods of coffee ground in the machine; 3 ) the Rovema line that packaged portion packs of ground coffee; 4) the Matrix line that packaged portion packs of ground coffee; 5) the Matrix Bib that packaged filter portion packs of ground coffee; 6) the Key Pack \#2 that packaged portion packs of ground coffee; 7) the Key Pack \#1 that packaged portion packs of ground coffee; 8) the Viking packaging line that packaged eight ounce and/ or two pound bags of whole bean and ground coffee; and 9) the bulk filler packaging line that packaged five pound whole bean bags and two pound whole bean and ground bags. Six table top grinders were used to grind up to five pounds of coffee at a time in the hand packaging area. The large grinder was located in the roast room and could grind up to 1,200 pounds per hour and was used by the portion pack, Viking and bulk filler lines. Another, smaller grinder was also located in the roast room and could grind approximately 80 pounds of coffee per load. Another grinder was located in the flavoring room and could grind approximately 80 pounds of coffee per load. Custom orders for flavored coffee were also processed in the packaging area. A packaging operator would take pre-weighed roasted coffee and mix with liquid flavorings in a small plastic bag. The small batch of flavored coffee would then be packaged. After packaging, bags and cans of coffee were stored in cardboard cases in the 
coffee finished goods area for one to two weeks before shipping out.

A breakroom area and offices were located in the space adjacent to the production floor. Administrative offices were located in two separate locations (upper level and lower level) in the same building.

\section{Personal Protective Equipment}

Employees were not required to wear a company uniform. Prior to the our survey in August 2017, state OSHA conducted personal air monitoring for diacetyl and 2,3-pentanedione exposures in the roast room. Based on the previous air sampling results collected on employees with job duties in the roast room, employees in the roast room were required to wear a half-mask or full-mask respirator equipped with organic vapor cartridges. Although no previous air sampling was performed in the flavoring room, the flavoring room attendant was also supplied with a half-mask respirator equipped with organic vapor cartridges for voluntary use when performing job duties in the flavoring room. A written respiratory protection program was in place for employees who performed job duties in the roasting area.

\section{Methods}

In August 2017, we conducted our initial visit to the facility. We held an opening meeting with management and employees, collected bulk samples and air samples, and performed a ventilation assessment. At the conclusion of our site visit, we held a closing meeting with management and employees. We visited the facility the following week to conduct a medical survey.

We had the following objectives for the health hazard evaluation:

1. Measure employees' exposure to diacetyl, 2,3-pentanedione, and 2,3-hexanedione during coffee processing;

2. Identify process areas or work tasks associated with emissions of diacetyl, 2,3-pentanedione, and 2,3-hexanedione;

3. Measure levels of $\mathrm{CO}$ and $\mathrm{CO}_{2}$ throughout the facility;

4. Assess ventilation systems and their effect on exposure levels;

5. Determine if employees had mucous membrane, respiratory, or systemic symptoms and the proportion of those symptoms that were work-related or aggravated by work;

6. Determine if employees had abnormal lung function test results; and

7. Compare employees' prevalence of respiratory symptoms and healthcare providerdiagnosed asthma to expected levels based on general population values.

\section{Industrial Hygiene Survey}

Sampling Times for Alpha-Diketones

We designed the sampling strategy to assess full-shift exposures and identify tasks and 
processes that were the greatest contributors to worker exposure to alpha-diketones.

Sampling was conducted over multiple days during each site visit. For diacetyl,

2,3-pentanedione, and 2,3-hexanedione, air samples were collected over seconds, minutes, and hours. Samples collected over hours can help determine average concentrations that can be compared to the NIOSH RELs for diacetyl and 2,3-pentanedione. These average concentrations might not tell us about short-term peak exposures that could be relevant to respiratory health, particularly when tasks are repeated multiple times per day. Therefore, during particular tasks, we collected air samples over several minutes. We also conducted instantaneous sampling over seconds to help identify point sources of alpha-diketones.

\section{Air Sampling and Analysis Using Modified Occupational Safety and Health Administration (OSHA) Methods 1013/1016}

We collected personal and area air samples for diacetyl, 2,3-pentanedione, and

2,3-hexanedione on silica gel sorbent tubes on multiple days during the industrial hygiene survey. The samples were collected and analyzed according to the modified OSHA sampling and analytical Methods 1013/1016 [OSHA 2008; OSHA 2010; LeBouf and Simmons 2017]. In accordance with the two methods, two glass silica gel sorbent tubes were connected by a piece of tubing and inserted into a protective, light-blocking cover. The tubes were connected in series to a sampling pump pulling air through the tubes at a flow rate of 50 milliliters per minute $(\mathrm{mL} / \mathrm{min})$. The sampling setup was attached to an employee's breathing zone or placed in an area basket in various places throughout the facility. For full-shift sampling, we collected two consecutive 3-hour samples and calculated the TWA concentration from the two samples, assuming that the total 6-hour monitoring results reflected a full work shift (8hour) TWA exposure. Although this may introduce some error, it is a conservative approach that is more protective of employees than the alternative assumption of no exposure during the last two hours of the shift. We refer to these samples as "full-shift samples" throughout this report. We also collected personal short-term task based samples in the same manner, but the sampling pump flow rate was $200 \mathrm{~mL} / \mathrm{min}$ as detailed in OSHA Methods 1013 and 1016 [OSHA 2008; 2010]. Sampling times were dependent on the duration of the task being performed.

Analyses of the samples were performed in the NIOSH Respiratory Health Division's Organics Laboratory. The samples were extracted for one hour in 95\% ethanol:5\% water containing 3-pentanone as an internal standard. Samples were analyzed using an Agilent 7890/7001 gas chromatograph/mass spectrometer system operated in selected ion monitoring mode for increased sensitivity compared to the traditional flame ionization detector used in OSHA Methods 1013 and 1016 [LeBouf and Simmons 2017].

A limit of detection (LOD) is the lowest mass that an instrument can detect above background and is a criteria used to determine whether to report a result from a sample. The LODs were 0.01 micrograms per sample ( $\mu \mathrm{g} / \mathrm{sample})$ for diacetyl, $0.012 \mu \mathrm{g} / \mathrm{sample}$ for 2,3-pentanedione, and $0.020 \mu \mathrm{g} / \mathrm{sample}$ for 2,3-hexanedione. These equate to $0.3 \mathrm{ppb}$ for diacetyl, $0.3 \mathrm{ppb}$ for 2,3-pentanedione, and $0.5 \mathrm{ppb}$ for 2,3-hexanedione for a typical fullshift air sample but will vary depending on the volume of air collected during the sampling period. The LODs for task samples are generally higher than typical LOD values for full- 
shift samples since the air volumes collected during task samples are lower. When the values presented in the report are from samples below the LOD they are denoted by a " $<$ " symbol.

\section{Air Sampling and Analysis Using Evacuated Canisters}

We collected instantaneous task-based and source air samples for VOCs including diacetyl, 2,3-pentanedione, and 2,3-hexanedione using evacuated canisters. We also collected instantaneous air samples before and after the work shift to determine if air concentrations of alpha-diketones increased over a work shift. The evacuated canister sampling setup consisted of a 450-mL evacuated canister equipped with an instantaneous flow controller that was designed for a short sampling duration (less than 30 seconds). For task-based air samples, a NIOSH employee placed the inlet of the flow controller by the employee's personal breathing zone as they performed their work task to replicate exposure. For source air samples, a NIOSH employee placed the inlet of the flow control directly at the source of interest.

The canister air samples were analyzed using a pre-concentrator/gas chromatograph/ mass spectrometer system pursuant to a published method validation study [LeBouf et al. 2012], with the following modifications: the pre-concentrator was a Model 7200 (Entech Instruments, Inc., Simi Valley, CA), and six additional compounds, diacetyl, 2,3-pentanedione, and 2,3-hexanedione, acetaldehyde, acetonitrile, and styrene, were included. At present, this canister method is partially validated [LeBouf et al. 2012] and not considered the standard method. The LODs were $0.78 \mathrm{ppb}$ for diacetyl, $1.08 \mathrm{ppb}$ for 2,3-pentanedione, and $1.92 \mathrm{ppb}$ for 2,3-hexanedione based on a three-times dilution factor. However, LODs are dependent on the pressure inside each canister after the samples have been collected, and they may be higher or lower than typical LOD values.

\section{Bulk Sampling and Headspace Analysis}

We used 50-mL sterile polypropylene centrifuge tubes to collect approximately $45-\mathrm{mL}$ bulk samples of liquid flavorings. For headspace analysis of alpha-diketones, we transferred bulk material into a sealed $40-\mathrm{mL}$ amber volatile organic analysis vial and let it rest for 24 hours at room temperature $\left(70^{\circ} \mathrm{F}\right)$ in the laboratory. Then $2 \mathrm{~mL}$ of headspace air was transferred to a 450-mL canister and pressurized to approximately 1.5 times atmospheric pressure. Using the canister analysis system, the concentrations were calculated in ppb of analytes in the headspace as an indicator of emission potential.

\section{Real-time (Continuous) Air Sampling}

We used Tiger VOC detector monitors (ION Science, Stafford, TX) to measure concentrations of total VOCs in the air. This sampling was conducted to identify areas where coffee could be releasing total VOCs. Areas where higher concentrations of total VOCs are measured help indicate areas where sampling to characterize specific exposures to alpha-diketones may be necessary. We also collected real-time measurements of $\mathrm{CO}_{2}, \mathrm{CO}$, temperature, and relative humidity (RH) using TSI Incorporated (Shoreview, MN) VelociCalc Model 9555-X MultiFunction Ventilation Meters equipped with Model 982 IAQ probes.

We continuously measured employee personal exposures to CO using a Dräger Pac ${ }^{\circledR} 7000$ personal single gas detector (Lübeck, Germany). The Dräger Pac ${ }^{\circledR} 7000$ was placed near the 
breathing zone of employees and worn by employees while they performed their work duties.

\section{Ventilation Assessment}

Physical measurements of spaces were taken with a Model DISTO E7100i laser-tape measure (Leica Geosystems AG, Heerbrugg, Switzerland) or a standard tape measure. Information on existing ventilation equipment, including make, model, and specified performance levels, was collected when possible. The size of the single ventilation system at the facility combined with limitations of the ventilation measurement equipment we had available precluded us from taking meaningful air flow measurements. Differential pressure measurements between adjacent spaces were taken under various ventilation scenarios using an Energy Conservatory DG-500 Pressure Gauge (Minneapolis, MN).

\section{NIOSH Medical Survey}

\section{Participants}

We invited all current employees to participate in the medical survey at the workplace on August 28-30, 2017. Participation was voluntary; written informed consent was obtained from each participant before testing. The survey included, in the order performed, a medical and work history questionnaire, quantification of exhaled nitric oxide, impulse oscillometry, spirometry, and if indicated, the administration of a bronchodilator with repeat impulse oscillometry and spirometry. We mailed participants their individual reports explaining their medical test results and recommended each participant provide the information to his/her personal physician.

\section{Questionnaire}

We used an interviewer-administered computerized questionnaire to ascertain symptoms and diagnoses, work history at this coffee roasting and packaging facility and other coffee or flavoring companies, and cigarette smoking history. Questions on respiratory health were derived from five standardized questionnaires, the European Community Respiratory Health Survey [Burney et al. 1994; ECRHS 2014], the American Thoracic Society adult respiratory questionnaire (ATS-DLD-78) [Ferris 1978], the International Union Against Tuberculosis and Lung Disease [Burney and Chinn 1987; Burney et al. 1989], and the Third National Health and Nutrition Examination Survey (NHANES III) [CDC 1996] and NHANES 2007-2012 questionnaires [CDC 2017a]. Some of the questions appeared on more than one of the standardized questionnaires. We also supplemented our questionnaire with additional respiratory and systemic symptom questions.

\section{Spirometry}

The purpose of the spirometry test was to determine a person's ability to move air out of their lungs. Test results were compared to expected normal values. The test included three measurements or calculations: 1) forced vital capacity (FVC), (the total amount of air the participant can forcefully blow out after taking a deep breath), 2) $\mathrm{FEV}_{1}$ (the amount of air that the participant can blow out in the first second of exhaling), and 3 ) the ratio of $\mathrm{FEV}_{1}$ to FVC. We used American Thoracic Society criteria for acceptability and repeatability [Miller et al. 2005]. 
We used a volume spirometer (dry rolling seal spirometer) to measure exhaled air volume and flow rates. We used equations for predicted values and lower limits of normal derived from NHANES III data to define abnormal spirometry [Hankinson et al. 1999]. We defined obstruction as an $\mathrm{FEV}_{1} / \mathrm{FVC}$ ratio less than the lower limit of normal with $\mathrm{FEV}_{1}$ less than the lower limit of normal; restriction as a normal $\mathrm{FEV}_{1} / \mathrm{FVC}$ ratio with $\mathrm{FVC}$ less than the lower limit of normal; and mixed obstruction and restriction as having $\mathrm{FEV}_{1}, \mathrm{FVC}$, and $\mathrm{FEV}_{1} / \mathrm{FVC}$ ratio all less than the lower limit of normal. We used the $\mathrm{FEV}_{1}$ percent predicted to categorize such abnormalities as mild ( $>70)$, moderate (60-69), moderately severe (50-59), severe (35-49), or very severe $(<35)$ [Pellegrino et al. 2005].

\section{Impulse Oscillometry}

Many occupational lung diseases (e.g., chronic obstructive pulmonary disease (COPD), asthma) involve the small airways; however, this part of the lung is difficult to evaluate noninvasively. Oscillometry is a helpful technology to understand the effects of occupational exposures on the small airways. There are no contraindications to the test as this test is conducted using regular breathing and does not require a forceful exhalation [Smith et al. 2005]. Spirometry can be normal despite respiratory symptoms or evidence of small airways disease on lung biopsy [King et al. 2011; Oppenheimer et al. 2007]; therefore, oscillometry results complement spirometry and can be used when spirometry is not possible because of a contraindication.

We used an impulse oscillometry machine (CareFusion Corp., San Diego, CA) to measure resistance $(\mathrm{R})$, the energy required to propagate the pressure wave through the airways, and reactance $(\mathrm{X})$, which reflects the viscoelastic properties of the respiratory system. The impulse oscillometry testing machine sends sound waves called pressure oscillations at different frequencies (e.g., 5 Hertz and 20 Hertz) into the airways to measure how airways respond to these small pressures. The test calculates 1) the airway resistance at different frequencies including 5 Hertz (R5) and 20 Hertz (R20), and the difference between R5 and R20 (DR5-R20); 2) the reactance at different frequencies including 5 Hertz (X5); 3) resonance frequency (Fres) which is the frequency where there is no airway reactance; and 4) the total reactance (AX) at all frequencies between 5 Hertz and the Fres. The predicted values for $\mathrm{R}$ and $\mathrm{X}$ were based on sex and age according to reference values recommended by the manufacturer [Vogel and Smidt 1994]. R5 was considered abnormal (elevated) if the measured value was equal to or greater than 140 percent of the predicted R5. X5 was considered abnormal (decreased) if the value of the predicted X5 minus measured X5 was equal to or greater than 0.15 kilopascals per liter per second $(\mathrm{kPa} /(\mathrm{L} / \mathrm{s}))$. DR5-R20 values greater than 30\% were considered abnormal and evidence of frequency dependence [Smith 2015]. We interpreted the test as normal if both the R5 and X5 were normal [Smith 2015]. We defined possible large (central) airways abnormality as a normal X5 and elevated R5 with no evidence of frequency dependence. We defined a possible small airways abnormality if there was evidence of frequency dependence and/or a decreased X5 with or without an elevated R5. We defined possible combined small (peripheral) and large (central airways) abnormality as a decreased X5 and elevated R5 with no evidence of frequency dependence. 
Bronchodilator Reversibility Testing for Impulse Oscillometry and Spirometry

If a participant had abnormal impulse oscillometry or spirometry, we repeated both tests after the participant received a bronchodilator inhaler medication (i.e., albuterol), which can open the airways in some individuals (e.g., asthmatics). For oscillometry, we defined reversibility (improvement) after bronchodilator administration as a decrease of at least $20 \%$ of either Fres or R5 or a decrease of $40 \%$ for AX. For spirometry, we defined reversibility (improvement) as increases of at least $12 \%$ and $200 \mathrm{~mL}$ for either $\mathrm{FEV}_{1}$ or FVC after bronchodilator administration.

\section{Fractional Exhaled Nitric Oxide (FeNO)}

We used the NIOX MINO ${ }^{\circledR}$ device (Aerocrine Inc., Morrisville, NC) to measure the amount of nitric oxide in the air the participant breathed out. Nitric oxide is a gas that is produced by the airways, and elevated levels can be a sign of eosinophilic airway inflammation in asthma [Dweik et al. 2011]. In adults, fractional nitric oxide concentration in exhaled breath levels above $50 \mathrm{ppb}$ are considered elevated. In adults with asthma, elevated levels may indicate that their asthma is uncontrolled [Dweik et al. 2011].

\section{Statistical Analysis}

Industrial Hygiene Survey and Ventilation Assessment

We performed analyses using Excel (Microsoft ${ }^{\circledR}$, Redmond, WA) and SAS version 9.4 (SAS Institute, Cary, NC). We created summary statistics by work area location, job title, and task. When the values presented in the report are from samples below the LOD they are denoted by a "<" symbol.

\section{Medical Survey}

We calculated frequencies and standardized morbidity ratios (SMRs) and their associated 95\% confidence intervals (CIs) using SAS version 9.4 (SAS Institute, Cary, NC). The SMRs compared prevalences of symptoms and spirometric abnormalities among participants to expected prevalences of a sample of the general population reflected in the NHANES III (1988-1994), and NHANES 2007-2012, adjusting for sex, race/ethnicity, age (less than 40 years old or 40 years or greater), and cigarette smoking categories (ever/never). For comparisons to the U.S. population, we used the most recent NHANES survey available for the specific comparisons.

\section{Results}

\section{Industrial Hygiene Survey Results}

Personal and Area Full-shift Air Sampling Results

Personal and area full-shift air sampling results using OSHA Method 1013/1016 can be seen in Table A1. We collected 51 personal and 108 area full-shift air samples over three days. Forty-nine of the 51 personal air samples were above the NIOSH REL for diacetyl of 5 ppb, and 36 were above the NIOSH REL for 2,3-pentanedione of 9.3 ppb. Employees with personal air samples above the NIOSH REL for diacetyl performed various tasks including roasting, flavoring ground and whole bean coffee, grinding coffee, packaging coffee, and 
administrative duties. Employees with personal air samples above the NIOSH REL for 2,3-pentanedione performed various tasks that included flavoring ground and whole bean coffee, grinding coffee, and packaging coffee. Personal air measurements for 2,3-hexanedione were lower than measurements of diacetyl and 2,3-pentanedione. Thirty-two of the 51 samples were below the LOD for 2,3-hexanedione, and the highest exposure $(2.0 \mathrm{ppb}$ 2,3-hexanedione) was measured on employees with tasks that included grinding coffee.

Ninety-seven of the 108 full-shift area air samples were above the NIOSH REL for diacetyl. Because area air samples are not personal air samples collected directly on an employee, the NIOSH RELs are not directly applicable to the results for exposure monitoring purposes. However, area air samples can highlight areas with higher exposure risk, and the RELs can be used as points of reference. The following areas had at least one 6-hour air level that exceeded the NIOSH REL for diacetyl: administrative areas (2.5 ppb-11.1 ppb), breakroom (2.0 ppb-7.9 ppb), finished product storage (6.0 ppb-19.6 ppb), flavoring room (10.8 ppb$23.7 \mathrm{ppb})$, green bean storage area (4.8 ppb-11.3 ppb), grinding areas (7.6 ppb-40.7 ppb), maintenance shop (6.5 ppb-13.1 ppb), all 11 packaging areas sampled (4.8 ppb-33.3 ppb), the upstairs offices entry (12.2 ppb-17.1 ppb), QC Lab (5.7 ppb-6.7 ppb), and roasting areas (5.5 ppb-11.7 ppb) (Table A1).

Sixty-eight of the 108 area full-shift air samples were also above the NIOSH REL for 2,3-pentanedione. The following areas had at least one 6-hour air level that exceeded the NIOSH REL for 2,3-pentanedione: administrative areas (2.6 ppb-11.6 ppb), finished product storage (4.7 ppb-23.8 ppb), flavoring room (13.0 ppb-213.7 ppb), green bean storage area (3.6 ppb-9.4 ppb), grinding areas (5.8 ppb-29.3 ppb), maintenance shop (6.6 ppb-12.6 ppb), all eleven packaging areas sampled ( $4.8 \mathrm{ppb}-28.4 \mathrm{ppb})$, and the entry to upstairs offices (12.7 ppb-19.1 ppb).

Areas near the large grinder, the grinder in the flavoring room, and the grinders used in the packaging area had some of the highest levels of diacetyl and 2,3-pentanedione. The highest 6-hour area air levels for diacetyl and 2,3-pentanedione measured at the large grinder were $40.7 \mathrm{ppb}$ diacetyl and $42.3 \mathrm{ppb}$ 2,3-pentanedione. The highest 6-hour area air levels for diacetyl and 2,3-pentanedione measured near the grinder in the flavoring room were $23.7 \mathrm{ppb}$ diacetyl and $213.7 \mathrm{ppb}$ 2,3-pentanedione. Levels measured near the packaging grinders also had high levels of 6-hour area air levels for diacetyl and 2,3-pentanedione (maximum: 33.3 ppb diacetyl and 26.6 ppb 2,3-pentanedione).

The flavoring weigh station area and area between the flavoring mixers had high 6-hour area air levels for 2,3-pentanedione (maximum: $105.6 \mathrm{ppb}$ measured at the flavoring weigh station; maximum: $192.3 \mathrm{ppb}$ measured in the area between the flavoring mixers); however, the levels of diacetyl measured in the same locations were much lower in comparison. The highest 6-hour area air levels for diacetyl measured at the flavoring weigh station and in the area between the flavoring mixers were $22.2 \mathrm{ppb}$ and $15.2 \mathrm{ppb}$, respectively.

\section{Task-Based Air Sampling Results}

Personal task air concentration results can be seen in Tables A2 and A3. We collected 46 
personal task air samples using OSHA Method 1013/1016. Task duration ranged from seven minutes to 28 minutes. We collected personal task air samples while employees cleaned a flavoring mixer, packaging machine, roaster, or grinders $(n=4)$; flavored coffee $(n=6)$, ground coffee $(n=7)$, scooped whole roasted beans into a packaging machine $(n=1)$, packaged coffee $(n=17)$, and roasted coffee $(n=11)$. The highest task-based TWA exposures to diacetyl (245.9 ppb) and second highest task-based TWA exposure to 2,3-pentanedione (228.4 ppb) were measured while an employee ground coffee (Table A2). The third highest task-based TWA exposures to diacetyl (36.2 ppb) and highest task-based TWA exposures to 2,3-pentanedione (723.5 ppb) were observed while an employee flavored roasted coffee. High levels of diacetyl and 2,3-pentanedione were also measured when employees packaged coffee (maximum: $38.1 \mathrm{ppb}$ diacetyl and $68.0 \mathrm{ppb}$ 2,3-pentanedione. The highest exposures to diacetyl and 2,3-pentanedione while employees performed cleaning tasks were measured while an employee cleaned the flavoring mixer (maximum: $28.3 \mathrm{ppb}$ diacetyl and 18.9 ppb 2,3-pentanedione). Diacetyl and 2,3-pentanedione air concentrations measured when employees roasted coffee were as high as $17.3 \mathrm{ppb}$ diacetyl and $13.0 \mathrm{ppb} 2,3$-pentanedione. Air concentrations measured when an employee scooped whole roasted beans into a packaging machine were $30.2 \mathrm{ppb}$ diacetyl and $23.6 \mathrm{ppb}$ 2,3-pentanedione.

Two 15-minute samples collected while an employee ground coffee (33.2 ppb-56.6 ppb), five samples collected while an employee packaged coffee (27.0 ppb-38.1 ppb), and one sample collected while an employee scooped roasted whole beans into a packaging machine $(30.2$ $\mathrm{ppb})$ were above the NIOSH STEL of $25 \mathrm{ppb}$ for diacetyl. Two 15-minute samples (35.4 ppb-115.7 ppb) collected while an employee ground coffee and three 15-minute samples collected while an employee packaged coffee (32.2 ppb-68.0 ppb) exceeded the NIOSH STEL of $31 \mathrm{ppb}$ for 2,3-pentanedione.

We collected 28 task-based personal samples near the breathing zone of employees using instantaneous canisters (Table A3). Levels of diacetyl and 2,3-pentanedione observed during certain tasks using instantaneous canisters were similar to the levels described above. The highest instantaneous levels were measured while employees ground coffee or worked with liquid flavorings. Instantaneous samples taken at the breathing zone of employees while they ground unflavored coffee at the large grinder ranged from $18.3 \mathrm{ppb}$ to $51.6 \mathrm{ppb}$ for diacetyl, and $12.9 \mathrm{ppb}$ to $49.2 \mathrm{ppb}$ for 2,3-pentanedione. Breathing zone samples taken while employees ground flavored coffee in the flavoring room ranged from less than $0.4 \mathrm{ppb}$ to 77.7 ppb diacetyl and $23.4 \mathrm{ppb}$ to $212 \mathrm{ppb} 2,3$-pentanedione. Instantaneous samples collected at the breathing zone of an employee while they weighed out liquid flavorings, added flavoring to the mixer, or scooped flavored coffee out of the flavoring mixer ranged from $12.5 \mathrm{ppb}$ to $509 \mathrm{ppb}$ for diacetyl and $7.6 \mathrm{ppb}$ to $211 \mathrm{ppb}$ for 2,3-pentanedione. Levels collected in the breathing zone of employees performing tasks at the roaster were lower. Breathing zone samples collected while an employee pulled a roasted bean sample to check the color of the beans while roasting or while they dumped roasted beans into the cooling bin ranged from less than $4.5 \mathrm{ppb}$ to $19.3 \mathrm{ppb}$ diacetyl and less than $3 \mathrm{ppb}$ to $15.5 \mathrm{ppb} 2,3$-pentanedione.

Source Air Sampling Results

Instantaneous evacuated canister concentrations for diacetyl and 2,3-pentanedione can be 
seen in Table A4. Instantaneous samples were less than 30 seconds in duration. We collected 25 source samples using evacuated canisters. The highest instantaneous source sample for diacetyl $(29,165 \mathrm{ppb})$ was measured at the dispenser of the grinder used by a bulk packaging employee, when the grinder was grinding 1 pound of JAVA coffee. The highest instantaneous source sample for 2,3-pentanedione (80,496 ppb) was measured at the face of the flavoring mixer while adding HG liquid flavoring to whole beans. Three instantaneous samples taken when flavoring was being added to whole beans had diacetyl levels less than the LOD but 2,3-pentanedione levels between $1581 \mathrm{ppb}$ and 80,496 ppb.

\section{Bulk Samples and Headspace Results}

Headspace results of diacetyl, 2,3-pentanedione, and 2,3-hexanedione for the bulk samples of liquid flavorings can be seen in Table A5. The highest air concentration of diacetyl (16,590 $\mathrm{ppb}$ ) was observed in the headspace of the CARM flavoring. The highest air concentration of 2,3-pentanedione $(92,637 \mathrm{ppb})$ was observed in the headspace of the HOC liquid flavoring. All samples were below the LOD for 2,3-hexanedione. Some liquid flavoring bulk samples (TM, BR, PERX, DUT) had no detectable diacetyl, 2,3-pentanedione, or 2,3-hexanedione in the headspace analyses. Additionally, some liquid flavoring bulk samples (AMAR, CARM, JI-COMPANY 2, HAZ, MAC, PEP, VAN) had detectable levels of diacetyl but no detectable 2,3-pentanedione. Alternatively, some liquid flavoring bulk samples (JMC-COMPANY 1) had no detectable diacetyl but high levels of 2,3-pentanedione.

\section{Real-time Monitoring: Carbon Dioxide ( $\left.\mathrm{CO}_{2}\right)$, Carbon Monoxide (CO), and Total Volatile} Organic Compounds (VOCs)

A summary of the real-time $\mathrm{CO}, \mathrm{CO}_{2}$, temperature, and total VOC monitoring results can be seen in Table A6. Levels of $\mathrm{CO}_{2}$ and $\mathrm{CO}$ measured at the grinder in the flavoring room ranged from $393 \mathrm{ppm}$ to $1,272 \mathrm{ppm}$ for $\mathrm{CO}_{2}$ and $0.7 \mathrm{ppm}$ to $101.7 \mathrm{ppm}$ for CO. Total VOC measurements at the grinder in the flavoring room ranged from less than $1 \mathrm{ppb}$ to $20,000 \mathrm{ppb}$. Levels of $\mathrm{CO}_{2}$ and $\mathrm{CO}$ measured at the grinders in the packaging area ranged from $473 \mathrm{ppm}$ to $1,496 \mathrm{ppm}$ for $\mathrm{CO}_{2}$ and $2.5 \mathrm{ppm}$ to $369.7 \mathrm{ppm}$ for $\mathrm{CO}$. Total VOC levels ranged from 16 $\mathrm{ppb}$ to $13,980 \mathrm{ppb}$ at the grinders in the packaging area. Area monitoring of the air near the large grinder in the roast room measured levels of $\mathrm{CO}_{2}$ and $\mathrm{CO}$ that ranged from 336 ppm to $1,174 \mathrm{ppm}$ for $\mathrm{CO}_{2}$ and $0.9 \mathrm{ppm}$ to $170.5 \mathrm{ppm}$ for $\mathrm{CO}$. Total VOC measurements at the large grinder in the roast room ranged from less than $1 \mathrm{ppb}$ to $5,792 \mathrm{ppb}$.

Levels of $\mathrm{CO}_{2}$ and $\mathrm{CO}$ at the Key Pack \#1 packaging machine ranged from 453 ppm to 676 ppm for $\mathrm{CO}_{2}$ and $3.1 \mathrm{ppm}$ to $10 \mathrm{ppm}$ for CO. Total VOC measurements at the Key Pack \#1 and Weigh Fill packaging machines ranged from less than $1 \mathrm{ppb}$ to 4,382 ppb. Levels of $\mathrm{CO}_{2}$ and $\mathrm{CO}$ at the large roaster ranged from $397 \mathrm{ppm}$ to $824 \mathrm{ppm}$ for $\mathrm{CO}_{2}$ and less than $0.1 \mathrm{ppm}$ to $12.4 \mathrm{ppm}$ for $\mathrm{CO}$.

A summary of continuous, real-time, personal measurements of CO can be seen in Table A7. TWA personal CO measurements ranged from $1 \mathrm{ppm}$ to $10.9 \mathrm{ppm}$ and were below the NIOSH REL of $35 \mathrm{ppm}$ for CO exposure. The large grinder operator in the roast room as well as the flavoring room attendant had maximum CO measurements (233-769 ppm and 208-270 ppm) that exceeded the NIOSH ceiling limit of $200 \mathrm{ppm}$. 


\section{Ventilation Assessment}

Ventilation in the roasting and packaging areas of the facility was provided by one Greenheck (Greenheck Fan Corporation, Schofield, WI) model DGX-P222-H35 make-up air-handling unit (MAHU) slab-mounted just outside the roasting area of the facility. The MAHU was capable of providing gas-fired heat to the facility when necessary, but did not have the ability to provide cooling. It was equipped with two 22 -inch blowers capable of providing up to 22,250 cubic feet per minute of $100 \%$ outdoor air to the roasting and packaging areas of the facility. Supply air was ducted from the MAHU through the wall in the roasting area. Inside the roasting area, the main supply duct split with one leg supplying air to the roasting area through a series of supply vents. The second leg traveled through the wall separating roasting from packaging and supplied outdoor air to the packaging area through a large duct sock. The MAHU operated on a variable frequency drive that varied the speed of the blowers to maintain a user-adjustable duct static pressure set point. Each leg of the main supply duct was equipped with a modulating damper that continuously adjusted the amount of supply air passing through each leg. The dampers were set up to work in conjunction with one another to maintain the roasting area under 0.01 inches of water gauge positive pressure in relation to the green bean storage area.

Air was exhausted from the roasting area through a large slot vent mounted low on the wall near the main grinder that was attached to a rooftop-mounted Greenheck model CUBE-300 belt-driven, upblast centrifugal exhaust fan (EF-1). The exhaust fan constantly removed 10,000-12,000 cubic feet per minute of air from the roasting space. The MAHU and EF-1 were both powered on together and remained on at all times when lights above the roasters were powered on. The combination of the MAHU and EF-1 maintained the roasting area under negative pressure to the adjacent green bean storage area.

Aside from the MAHU and EF-1, the only other ventilation equipment was a small exhaust fan mounted through the wall high in the flavoring room. The fan was powered on and off with a wall switch and used any time flavoring activities were performed in the flavoring room. The administrative areas, breakroom, and upstairs offices were all served by separate air-handling units that were not assessed during our visit.

Differential pressure measurements taken between two adjacent spaces showed that the break room was under positive pressure compared to the production area and the administrative offices. The administrative offices and the label room were under negative pressure to the production space. The upstairs office area was generally neutral to the production area. These results were determined during our visit, but they could be impacted day to day by variations in the weather, doors or windows being opened or closed, or operating states (on vs. off) of various ventilation systems.

\section{Medical Survey Results \\ Demographics}

Thirty-three of 44 employees (75\%) participated in the medical survey. The majority of participants were female (58\%) and white $(76 \%)$, with a mean age of 39 years and average tenure at the company of 6 years. Eighteen (55\%) participants were current or former smokers. 
Thirty-two (97\%) of 33 medical survey participants reported working in or entering the production area for an average of 32 hours per week, ranging from one to 40 hours a week. Thirty (91\%) of 33 participants reported being within an arm's length of roasted coffee in one or more areas of the production process. Twenty-one (64\%) of 33 participants worked their entire shift in the production area processing coffee.

\section{Symptoms and Self-Reported Diagnoses}

The prevalence of symptoms over the last year and last four weeks at the time of the survey are listed in Table A8. In the last year, nose symptoms were the most commonly reported symptom $(n=14,42 \%)$, followed by eye symptoms $(n=13,39 \%)$. Eight $(24 \%)$ of 33 participants who reported nose or eye symptoms reported these symptoms were better away from work. Some production employees noted that their nose or eye symptoms were caused or aggravated by green bean coffee burlap bags, dust, flavorings, grinding coffee, or packaging coffee.

Chest wheezing or whistling $(\mathrm{n}=10,30 \%)$, shortness of breath on level ground or walking up a slight hill $(n=8,24 \%)$, and breathing trouble $(n=8,24 \%)$ in the last 12 months were the most commonly reported lower respiratory symptoms at the time of the survey. Two (20\%) of 10 participants who reported wheeze stated these symptoms were better away from work, and four $(50 \%)$ of eight participants who reported breathing trouble stated these symptoms were better away from work. Of the eight participants who reported shortness of breath, two reported that their shortness of breath began after they started employment at the facility. Some employees reported that their lower respiratory symptoms were caused or aggravated by dust and flavorings. Twelve (36\%) of 33 participants reported systemic symptoms. Flulike achiness or achy joints was the most commonly reported systemic symptom $(n=10$, $30 \%$ ). Five (15\%) of 12 participants who reported systemic symptoms reported that their systemic symptoms were aggravated at work.

Nine participants reported a diagnosis of hay fever or nasal allergies; two of the nine were diagnosed after beginning employment at this coffee roasting and packaging facility. Eight participants reported being diagnosed with asthma in their lifetime, while seven reported a current diagnosis with asthma. Two participants reported receiving an asthma diagnosis after beginning their employment at this coffee roasting and packaging facility. Two participants reported a diagnosis of chronic bronchitis prior to employment at this facility. Six participants reported a diagnosis of gastroesophageal reflux disease (GERD), and three participants were diagnosed with GERD after beginning employment at this coffee roasting and packaging facility. No participants reported emphysema, COPD, bronchiolitis obliterans, interstitial lung disease, hypersensitivity pneumonitis, chemical pneumonitis, sarcoidosis, heart disease, or vocal cord dysfunction.

\section{Medical Tests}

Thirty (91\%) of 33 medical survey participants performed two or more medical tests. Four $(13 \%)$ of 30 participants who performed spirometry had test results interpreted as abnormal: one participant had a mild obstructive pattern, and three participants had mild restrictive patterns. None had significant improvement in spirometry after taking a bronchodilator. 
Thirteen (43\%) of 30 participants who performed impulse oscillometry had test results interpreted as abnormal; 11 were consistent with small airways abnormality, one consistent with large airways abnormality, and one consistent with small and large airways abnormality. Six $(55 \%)$ of the nine participants who took a bronchodialator showed significant improvement in impulse oscillometry. Two (6\%) of 31 participants who performed exhaled nitric oxide tests had tests interpreted as elevated.

\title{
NHANES Comparison of Symptoms and Diagnoses
}

The SMRs for ever receiving a physician diagnosis of asthma and current asthma diagnosis were elevated at 3.1 and 4.1, respectively (Table A9). The SMR for having phlegm for three consecutive months or more during the year was 2.5. Prevalences for shortness of breath, wheeze, cough, sinus problems, and nose and eye symptoms were not elevated abnormalities in comparison to the general U.S. population, adjusted for age distribution, race/ethnicity, sex, and smoking history.

\section{Discussion}

Overall, the highest area samples for total VOCs, CO, diacetyl, and 2,3-pentanedione were observed in areas where roasted coffee was ground or flavored (areas near the large grinder, the grinder in the flavoring room, and the packaging grinders). Diacetyl, 2,3-pentanedione, 2,3-hexanedione, other VOCs, and other compounds such as $\mathrm{CO}_{2}$ and $\mathrm{CO}$ are naturally produced when coffee beans are roasted, and grinding the roasted coffee beans produces greater surface area for the off-gassing of these chemicals [Anderson et al. 2003; Akiyama et al. 2003; Daglia et al. 2007; Newton 2002; Nishimura et al. 2003; Raffel and Thompson 2013]. In addition, flavorings added to roasted coffee can contain diacetyl or 2,3-pentanedione. Occupational exposure to diacetyl and 2,3-pentanedione can cause loss of lung function and the lung disease obliterative bronchiolitis [NIOSH 2016]. Some employees developed obliterative bronchiolitis while working at another coffee roasting and packaging facility that used flavorings and had elevated levels of diacetyl and 2,3-pentanedione [CDC 2013; Bailey et al. 2015; Duling et al. 2016].

\begin{abstract}
Alpha-Diketones
Personal Air Sampling

Forty-nine personal full-shift air samples collected on employees who perform various duties inside the facility using standard OSHA methods were above the NIOSH REL for diacetyl. The highest personal full-shift air samples for diacetyl (20 ppb to $47.3 \mathrm{ppb}$ diacetyl) were collected on employees with grinding (47.3 ppb), packaging (27.0 ppb), and flavoring (20.0 $\mathrm{ppb}$ ) duties. Thirty-six personal air samples collected on employees with various production tasks were above the NIOSH REL for 2,3-pentanedione. The highest personal full-shift air samples for 2,3-pentanedione (42.3 ppb to $177.9 \mathrm{ppb} 2,3$-pentanedione) were collected on employees with flavoring (177.9 ppb), packaging (63.7 ppb), and grinding (42.3 ppb) duties.
\end{abstract}

As noted earlier, the RELs should be used as a guideline to indicate when steps should be taken to reduce exposures in the workplace. The risks associated with the measured levels 
of diacetyl and 2,3-pentanedione are higher than NIOSH recommends. As described in the quantitative risk assessment from the NIOSH Criteria Document (Tables 5-27 and 5-34) [NIOSH 2016], after a 45-year working lifetime exposure to $20 \mathrm{ppb}$ (a concentration lower than the highest concentration measured at this facility), NIOSH estimated that about 5 in 1,000 workers would develop reduced lung function ( $\mathrm{FEV}_{1}$ below the lower limit of normal). NIOSH predicted that around 5 in 10,000 workers exposed to diacetyl at 20 ppb would develop more severe lung function reduction ( $\mathrm{FEV}_{1}$ below $60 \%$ predicted, defined as at least moderately severe by the American Thoracic Society [Pellegrino et al. 2005]). After a 45-year working lifetime exposure to $50 \mathrm{ppb}$ (a concentration higher than the highest concentration measured at this facility), NIOSH estimated that about 12 in 1,000 workers would develop reduced lung function $\left(\mathrm{FEV}_{1}\right.$ below the lower limit of normal). NIOSH predicted that about 1 in 1,000 workers exposed to diacetyl at $50 \mathrm{ppb}$ would develop more severe lung function reduction. The effects of a working lifetime exposure at $47 \mathrm{ppb}$ would be somewhat less than those at for $50 \mathrm{ppb}$. NIOSH recommends keeping diacetyl concentrations below $5 \mathrm{ppb}$ because at this level, the risk of reduced lung function after a working lifetime of exposure is below 1 in 1,000 workers. NIOSH recommends taking steps to reduce diacetyl exposures to below the REL of $5 \mathrm{ppb}$ whenever possible.

\section{Area Air Sampling}

All production and administrative areas sampled, to include the offices, breakroom, finished product storage, flavoring room, green bean storage area, grinding areas, maintenance shop, packaging areas, entry to upstairs offices, QC lab, and roasting areas had air levels that exceeded the NIOSH REL for diacetyl. Areas in finished product storage, the flavoring room, the green bean storage area, grinding areas, the maintenance shop, packaging areas, and the entry to upstairs offices also had air levels that exceeded the NIOSH REL for 2,3-pentanedione. Of the 108 full-shift area samples, 97 were above the NIOSH REL for diacetyl and 68 were above the NIOSH REL for 2,3-pentanedione. Areas where coffee was ground or flavored (near the large grinder, the grinder in the flavoring room, and the grinders used in the packaging area) consistently had the highest diacetyl (maximum TWA: $23.7 \mathrm{ppb}$ to $40.7 \mathrm{ppb}$ ) and 2,3-pentanedione (maximum TWA: $26.6 \mathrm{ppb}$ to $213.7 \mathrm{ppb}$ ) air levels. We note that NIOSH RELs are intended to be directly compared to personal measurements; therefore, an area air sample that exceeds a NIOSH REL is only an indication of potential personal exposures.

\section{Task-Based Exposures}

Coffee processing involves multiple tasks that may cause intermittent exposure to diacetyl and 2,3-pentanedione. Traditional full-shift sampling will not characterize these intermittent, peak exposures. Measured short-term peak exposures contribute to average full-shift exposures and can help identify sources and processes that generate diacetyl and 2,3-pentanedione and that can be targeted with engineering controls. Evaluating intermittent and task-based exposures to diacetyl and 2,3-pentanedione is difficult with current validated sampling methods (OSHA Methods 1013/1016). Since tasks are so sporadic in coffee processing, with some only lasting a few seconds or minutes, we used instantaneous evacuated canisters to sample tasks that were only a few seconds to minutes long and OSHA Methods 1013/1016 for longer duration tasks. We sampled by task, with varying durations, 
to understand which tasks may have contributed to higher exposures of diacetyl and 2,3-pentanedione.

Our task-based air sampling revealed that some tasks had higher air concentrations of diacetyl and/or 2,3-pentanedione than other tasks. The highest TWA exposures to diacetyl (245.9 ppb) and second highest exposure to 2,3-pentanedione (228.4 ppb) were measured while an employee ground coffee (Table A2). We also measured higher exposures to diacetyl (36.2 ppb) and 2,3-pentanedieone (723.5 ppb) during flavoring of roasted coffee. Two 15-minute samples collected while an employee ground coffee, one sample collected while an employee scooped roasted whole beans into a packaging machine, and five samples while an employee packaged coffee were above the NIOSH STEL for diacetyl. Additionally, two 15-minute samples collected while an employee ground roasted coffee and three samples collected while an employee packaged coffee were also above the NIOSH STEL for 2,3-pentanedione.

We also measured diacetyl and 2,3-pentanedione using instantaneous sampling, in which sample duration was less than 30 seconds. These instantaneous samples were collected to identify and describe short-duration tasks and point sources of diacetyl and 2,3-pentanedione. The highest instantaneous levels taken at the breathing zone of employees were measured while employees ground coffee or worked with liquid flavorings. The highest instantaneous levels of diacetyl (509 ppb) and second highest levels of 2,3-pentanedione (211 ppb) collected at the breathing zone of employees were measured while an employee weighed flavorings and/or flavored whole bean coffee. Breathing zone samples taken while employees ground flavored coffee in the flavoring room were as high as $77.7 \mathrm{ppb}$ diacetyl and 212 ppb 2,3-pentanedione. Instantaneous samples taken at the breathing zone of employees while they ground unflavored coffee were as high as $51.6 \mathrm{ppb}$ for diacetyl, and $49.2 \mathrm{ppb}$ for 2,3-pentanedione. The liquid flavorings as well as the greater surface area for off-gassing that is produced during grinding could have resulted in the higher air concentrations observed while employees performed flavoring and grinding tasks [Akiyama et al. 2003].

\section{Source Air Sampling}

The highest instantaneous sources sample for diacetyl $(29,165 \mathrm{ppb}$ and $12,388 \mathrm{ppb})$ was measured at the dispenser of the packaging grinder when a bulk packaging employee was grinding one pound or five pounds of coffee. As mentioned above, grinding creates a greater surface area for off-gassing from roasted coffee beans, which may have resulted in the higher air concentrations observed during grinding [Akiyama et al. 2003]. The highest instantaneous source sample for 2,3-pentanedione $(80,496 \mathrm{ppb})$ was measured at the face of the flavoring mixer while an employee added HG flavoring to whole beans. Elevated levels of diacetyl (475 ppb) and 2,3-pentanedione (676 ppb) were also observed at the dispenser of the grinder in the flavoring room while the flavoring room attendant was grinding 40 pounds of ground coffee. Elevated levels of diacetyl (247 ppb) were also observed during packaging of ground coffee at the portion pack machine.

\section{Bulk samples}

Diacetyl (2,3-butanedione) and 2,3-pentanedione are sometimes added as ingredients in 
liquid flavorings for coffee. Of the 13 bulk samples of liquid flavorings that we collected, seven samples had diacetyl but no detectable 2,3-pentanedione, and one sample had high levels of 2,3-pentanedione but no detectable diacetyl in the headspace analyses. We observed both diacetyl and 2,3-pentanedione in the headspace of one sample. Four samples had no detectable levels of diacetyl, or the chemically similar alpha diketones, 2,3-pentanedione, or 2,3-hexanedione. Differences in liquid flavoring formulations and diacetyl and 2,3-pentanedione content help explain why some air samples collected while employees performed flavoring tasks had measured levels of 2,3-pentanedione that were 20-fold higher than diacetyl.

\section{Real-time Sampling for Carbon Monoxide (CO), Carbon Dioxide ( $\left.\mathrm{CO}_{2}\right)$, and Volatile Organic Compounds (VOCs)}

Our real-time monitoring found that the highest overall levels of total $\mathrm{CO}, \mathrm{CO}_{2}$, and $\mathrm{VOCs}$ were observed at the packaging grinders, flavoring room grinder, and large grinder. None of the personal TWA measurements of CO exceeded the NIOSH REL (35 ppm) or OSHA PEL $(50 \mathrm{ppm})$. However, the area near the packaging grinders as well as personal samples for CO collected on a grinder operator and flavoring room attendant exceeded the NIOSH ceiling (200 ppm) for CO. The NIOSH ceiling limit should not be exceeded at any time. All $\mathrm{CO}_{2}$ measurements were below the NIOSH REL (5,000 ppm) and OSHA PEL (5,000 ppm).

\section{Ventilation}

As can be seen in Table A1, concentrations of alpha-diketones in area samples were found to be above the NIOSH RELs throughout the facility, including in the administrative areas. Elevated levels of diacetyl and 2,3-pentanedione indicate that ventilation equipment in use at the time of our visit was not adequate to maintain airborne concentrations at acceptable levels during normal roasting, flavoring, and packaging operations.

The combination of the MAHU and EF-1 maintained the roasting area under negative pressure to the adjacent green bean storage area. We also determined air from the production area could potentially enter non-production areas under the conditions of testing. Air will flow from an area of higher pressure (or "positive" pressure) to an area of lower pressure (or "negative" pressure). Generally, the production area would be expected to have the highest concentrations of airborne contaminants. To keep these contaminants confined to the production area and prevent them from spreading into adjacent areas, the production area should be maintained under negative pressure relative to the adjacent spaces. This would ensure that air from the adjacent spaces flows into the production area and not the other way around. During our visit, we found that the production space was appropriately negative to the break room. However, the administrative area and label room were under negative pressure relative to the production area, allowing airborne contaminants generated during production to be pulled into those spaces and potentially contributing to personal sample measurements in the administrative area that exceeded the NIOSH REL for diacetyl. The upstairs office area was neutral to production. The operational state of various air-handling units and make-up air units throughout the facility could make pressure differentials better or worse. Loading dock doors being opened or closed will also effect pressure differentials. Constant negative pressure in the production area relative to non-production areas is needed 
to keep contaminants from the production space from migrating to non-production areas. To maintain consistent negative pressure in the production area, additional exhaust systems are needed. These systems could consist of local exhaust at contaminant sources, general exhaust fans through the walls or ceiling, or a combination of both.

\section{Local exhaust ventilation}

Local exhaust ventilation systems can capture contaminants when generated and remove contaminants before inhalation by employees can occur. Local exhaust ventilation systems generally consist of hoods or enclosures, duct work, or fans. Depending on the contaminant and whether air is recirculated, filters or other air cleaning technologies can also be incorporated. After properly designed local exhaust ventilation systems are installed, overall workplace exposure levels can be reduced by removing contaminants at the source. The flavoring room mixers, grinders, and various point-sources on coffee packaging lines could be modified with local exhaust ventilation that would help reduce overall alpha-diketone concentrations in the facility. Additional sampling can be done to further identify point sources of alpha-diketone emissions associated with each process. If additional point sources are identified, additional local exhaust ventilation can be used to reduce employee exposures.

\section{General exhaust or dilution ventilation}

In an ideal environment, good general ventilation provides fresh air into the space and removes contaminated air. General exhaust ventilation allows contaminants to be emitted into the workplace and then dilutes the concentration of the contaminant to acceptable levels. This is generally done by providing outdoor air (or recirculated, filtered air) to the space to provide dilution. Simultaneously, air is exhausted from the space to remove the contaminants. The relationship between supply air and exhaust air flow rates can be used to help maintain appropriate pressure relationships. If more air is supplied than exhausted, the space will generally be under positive pressure, which allows contaminants to migrate from the space to adjacent areas. Conversely, exhausting more air than is supplied, maintains the space under negative pressure which helps contain the contaminants in the area where they are generated.

During our visit, the general ventilation provided by the combination of the MAHU and EF-1 was the only ventilation in the production space, except for the small exhaust fan in the flavoring room, which properly maintained that space under negative pressure to the rest of the production areas when the fan was powered on. Adjustments to the MAHU and EF-1 may be possible to create more airflow and a stable negative pressure relationship in the roasting and grinding area. Providing more outdoor air flow will enhance dilution and removal of contaminants; however, there will be additional energy costs associated with heating the outside air introduced into the facility for some of the year. There was a large, functional exhaust fan mounted in the ceiling between the roasters and grinders, but it was reportedly not used on a regular basis. Operating the fan in the ceiling between the roasters and grinders anytime roasting and grinding activities are actively occurring would help maintain the roasting and grinding area under negative pressure. Ensuring that the roasting and grinding area is maintained under negative pressure could help prevent any airborne contaminants generated in the roasting and grinding areas from migrating to the adjacent warehouse and packaging spaces. Care should be taken to ensure the flavoring room is maintained under 
negative pressure to roasting and grinding. A ventilation system expert can help meet all ventilation requirements in the production space and other areas of the building occupied by employees.

\section{Relocation or enclosure of specific processes}

Engineering controls may help mitigate exposures in the roasting and grinding area, along with the packaging area. In some cases, consideration should be given to relocating processes or specific pieces of equipment to simplify the implementation of engineering controls. One example would be to move the flavoring mixers across the room so that they are located beside the flavoring grinder under the exhaust fan through the wall. Another example would be relocating the large grinders to a more isolated area of the plant. For example, implementation of local exhaust ventilation at the grinders would be simplified if the large grinders were relocated to an area near an exterior wall. The grinders could then be isolated in their own room, which could be ventilated separately from the larger space. Having a separate room with separate ventilation for storing full containers of whole-bean or ground coffee may also further reduce concentrations of alpha-diketones in the overall production space.

\section{Medical Survey}

Overall, mucous membrane symptoms, specifically nose and eye symptoms, were the most commonly reported symptoms. Some production employees reported their mucous membrane symptoms were caused or aggravated by green bean coffee burlap bags, dust, flavorings, or grinding coffee. Coffee dust is an organic dust and, as noted earlier, exposure to coffee dust is known to cause respiratory symptoms and is a known risk factor for occupational asthma [Karr et al. 1978; Zuskin et al. 1979, 1985, 1993; Thomas et al. 1991; Sakwari et al. 2013].

Upper respiratory disease, such as allergic rhinitis (hay fever, nasal allergies) and sinusitis, are sometimes associated with lower respiratory symptoms and may precede the diagnosis of asthma [Shaaban et al. 2008; EAACI Task Force on Occupational Rhinitis et al. 2008; Rondón et al. 2012, 2017; Sahay et al. 2016]. Upper respiratory involvement (e.g., rhinitis, sinusitis) can result in suboptimal control of asthma. Some ( 8 of $17 ; 47 \%$ ) participants that reported lower respiratory symptoms also reported nasal or sinus problems or physiciandiagnosed hay fever or nasal allergies. Green coffee dust is thought to be a more potent allergen than roasted coffee dust because roasting destroys some of the allergenic activity [Lehrer et al. 1978]. As discussed in the recommendation section, to prevent symptoms related to green coffee dust and chaff, make N95 disposable filtering-face piece respirators available for voluntary use when emptying burlap bags of green beans or when emptying the chaff containers or cleaning the green bean storage area.

The number of participants ever diagnosed with asthma by a physician $(n=8 ; 24 \%)$ and participants who had current asthma $(n=7,21 \%)$ were significantly higher than expected compared with the U.S. population with SMRs of 3.1 and 4.1, respectively. Two of these participants were diagnosed after beginning work at this coffee roasting and packaging facility. Of the seven participants with current asthma, six (86\%) reported their asthma-like 
symptoms were related to or aggravated at work. Asthma symptoms often improve when away from exposures that trigger symptoms while other lung diseases such as obliterative bronchiolitis or COPD generally do not improve. Nine (53\%) of the 17 participants who reported lower respiratory symptoms stated those symptoms were related to or aggravated by work.

Spirometry can be used to help detect and follow individuals with asthma and other lung diseases such as obliterative bronchiolitis or COPD. Spirometry can show if air is exhaled from the lungs more slowly than normal (i.e. obstructive abnormality) or if the amount of air exhaled is less than normal (i.e., restrictive abnormality). At this facility, three workers had mild restrictive abnormalities, and one had a mild obstructive abnormality on spirometry. In asthma, there is intermittent airways obstruction which is reversible after treatment with bronchodilator medications (e.g., albuterol). In obliterative bronchiolitis, scar tissue prevents the small airways (bronchioles) from opening up when albuterol is given. In other words, the airways are fixed and not responsive (reversible) to bronchodilator medicine. The obstructed airways prevent rapid emptying of the lung air sacs (alveoli) during exhalation. This explains why the respiratory symptoms of those with occupational obliterative bronchiolitis do not tend to improve when away from work-related exposures; however, avoidance of further exposure can stop progression of the disease [Akpinar-Elci et al 2004].

Spirometry and impulse oscillometry measure different things. Spirometry assesses airflow and is the breathing test typically used to screen for flavoring-related lung disease. Impulse oscillometry assesses the airways response to a sound or pressure wave and has not commonly been used to screen for flavoring-related lung disease. In general, during the impulse oscillometry test, a small pressure impulse (sound wave) is imposed upon the inspiratory and expiratory airflow during normal tidal breathing. This pressure wave causes a disturbance in the airflow and pressure, and the response of the airways (i.e., change in pressure to change in flow) is a measure of the resistance to airflow in the airways [Desiraju and Agrawal 2016]. Impulse oscillometry may be useful as an indirect measure of airflow obstruction and helpful in individuals not able to perform forced breathing maneuvers that are required during the spirometry test. The impulse oscillometry test has been used for many years to measure changes in the airways of children with lung problems such as asthma and cystic fibrosis [Song et al. 2008; Komarow et al. 2011; Shi et al. 2012; Schulze et al. 2016]. More recently, impulse oscillometry has been used to investigate lung problems in adults exposed to dust or chemicals, such as World Trade Center emergency responders and soldiers returning from deployment overseas [Oppenheimer et al. 2007; Berger et al. 2013; Weinstein et al. 2016]. Over the years, researchers have developed reference (predictive) equations for different populations of children for oscillometry [Malmberg et al. 2002; Park et al. 2011; Lee et al. 2012; de Assumpção et al. 2016]. For adults, there are fewer reference equations available for oscillometry [Vogel and Smidt 1994; Newbury et al. 2008; Schulz et al. 2013]. The predicted values we used for oscillometry measures were based on gender and age according to references values recommended by the manufacturer. Unlike predictive equations used for spirometry, the impulse oscillometry reference equations we used did not take into account height, race, or smoking status [Vogel and Smidt 1994]. 
Of the 20 participants with upper and lower respiratory symptoms, 11 reported that their symptoms were aggravated by work. We also found a four-fold excess of workers with a current physician diagnosis of asthma. Sixteen (50\%) of 32 participants had abnormalities on lung function testing. These results suggest a burden of respiratory problems in this workforce. The lung function abnormalities we found are not specific to a particular respiratory problem or disease. They could be related to workplace exposures or to other factors. Indeed, some employees had respiratory diagnoses that preceded employment at this facility, but other participants reported developing lower respiratory symptoms since beginning to work at this facility. We mailed each participant their individual lung function test results with an explanation of the results and recommended each participant provide the information to their personal physician.

We recommend starting a medical monitoring program because air sampling detected employee exposures to diacetyl and 2,3-pentanedione that exceeded the NIOSH RELs, and there were a number of participants with abnormal breathing tests or history of lower respiratory symptoms. All production employees and any employees that assist with production tasks (e.g., roasting, interacting with open storage bins/containers of roasted coffee, grinding, weighing, or packaging coffee) should participate in the workplace medical monitoring program. A medical monitoring program is a means of early identification of employees who may be developing lung disease (e.g., asthma, obliterative bronchiolitis) and can help prioritize interventions to prevent occupational lung disease. The NIOSH medical survey results can serve as a baseline for employees who participated, if they choose to share these results with the provider. In a workplace with risk of occupational lung disease, prevention of smoking-related lung disease is important and makes the detection of workrelated adverse effects easier. The Centers for Disease Control and Prevention offers tools and resources for setting up a smoking cessation program [CDC 2017b].

\section{Conclusions}

We identified specific work tasks that resulted in air concentrations of diacetyl and 2,3-pentanedione that exceeded the NIOSH RELs for diacetyl and 2,3-pentanedione. High full-shift and task-based diacetyl and 2,3-pentanedione exposure measurements were observed on employees that ground coffee, flavored coffee, and packaged coffee. We observed high instantaneous levels of diacetyl and 2,3-pentanedione during grinding, flavoring, and packaging ground coffee tasks. Areas with unflavored and flavored ground coffee present, specifically the large grinder, the packaging grinders, and the grinder in the flavoring room, had the highest levels of diacetyl, 2,3-pentanedione, 2,3-hexanedione, and $\mathrm{CO} . \mathrm{CO}_{2}$ levels were low throughout most of the facility. However, $\mathrm{CO}$ levels measured on a grinding operator, a flavoring room attendant, and in the areas near the packaging grinders exceeded the NIOSH ceiling limit of $200 \mathrm{ppm}$.

Differential pressure measurements taken between two adjacent spaces showed that the break room was under positive pressure compared to the production area and the administrative offices. The administrative offices and the label room were under negative pressure to the 
production space. The upstairs office area was neutral to the production area. These results could be impacted day to day by variations in the weather, doors or windows being opened or closed, or operating states (on vs. off) of various ventilation systems. All general ventilation in the production space was provided by the MAHU, EF-1, and a small exhaust fan mounted through the wall high in the flavoring room. The flavoring exhaust fan was powered on and off with a wall switch and was used any time flavoring activities were performed in the flavoring room. Adjustments to the MAHU and EF-1 may be possible to create more dilution air flow and a more stable negative pressure relationship in the roasting and grinding area. Operating the large ceiling-mounted exhaust fan between the roasters and grinders anytime roasting and grinding is performed would help maintaining the roasting and grinding area under more negative pressure. This could help prevent any airborne contaminants generated there from migrating to the adjacent warehouse and packaging spaces. However, care should be taken to ensure the flavoring room is maintained under negative pressure compared with the roasting and grinding area. Those decisions should be made as part of an overall plan to improve engineering controls at the facility. A ventilation system expert should be consulted to help meet all ventilation requirements in the facility. Consideration should also be given to relocating equipment or processed to make the implementation of engineering controls easier.

Overall, mucous membrane symptoms, specifically eye and nose symptoms, were the most commonly reported symptoms in the last year. Some production employees reported their mucous membrane symptoms were better away from work and noted that these symptoms were aggravated by dust, flavorings, or grinding coffee. Chest wheezing or whistling, shortness of breath on level ground or walking up a slight hill, and breathing trouble were the most commonly reported lower respiratory symptoms. Participants reported ever being diagnosed with asthma and having a current asthma diagnosis significantly higher than expected compared with the U.S. noninstitutionalized population of the same age, race/ ethnicity, sex, and cigarette smoking distribution. Sixteen (50\%) of 32 medical survey participants had abnormal medical tests. We recommend a medical monitoring program to help identify any employees who may be developing lung disease (e.g., asthma, obliterative bronchiolitis) and to help management prioritize interventions to prevent occupational lung disease. All production workers and employees that assist with production tasks (e.g., roasting, interacting with open storage bins/containers of roasted coffee, grinding, weighing, or packaging coffee) should participate in the workplace medical monitoring program.

\section{Recommendations}

On the basis of our findings, we recommend the actions listed below. We encourage this coffee roasting and packaging facility to use a labor-management health and safety committee or working group to discuss our recommendations and develop an action plan. Our recommendations are based on an approach known as the hierarchy of controls. This approach groups actions by their likely effectiveness in reducing or removing hazards. In most cases, the preferred approach is to eliminate hazardous materials or processes and install engineering controls to reduce exposure or shield employees. 


\section{Engineering Controls}

Engineering controls reduce employees' exposures by removing the hazard from the process or by placing a barrier between the hazard and the employee. Engineering controls protect employees effectively without placing primary responsibility of implementation on the employee.

1. Consult with a ventilation engineer to install local exhaust ventilation at the flavoring room mixers and the grinder in the flavoring room. Consider moving the flavoring room mixers so that they are located beside the flavoring grinder and under the existing exhaust fan to make the implementation of engineering controls easier. Until additional local exhaust ventilation can be installed, operate the flavoring room exhaust fan at all times when employees are present in the facility, not just when flavoring coffee and grinding flavored coffee. The flavoring room should be the area under negative pressure meaning that air from all other adjacent areas should flow through the flavoring room. At no time should air from the flavoring room flow into other adjacent areas. As other modifications to engineering controls are made, ensure the flavoring room remains negative to all other spaces.

2. Consult with a ventilation engineer to install local exhaust ventilation at all grinders to include the large grinder, the packaging grinders, and the small grinder. If possible, relocate the grinders to an area with little or no bystander foot traffic to minimize potential exposure risks to employees not directly using the grinders. Relocating the grinders to an exterior wall may make implementation of engineering controls easier.

3. Consult with a ventilation engineer to ensure that administrative spaces, including the upstairs offices and the breakroom, are kept under positive pressure compared to the production space. Ensure all doors between the production space and non-production space are closed at all times.

4. Work with the ventilation engineer to determine if additional outdoor air can be supplied to the roasting room, flavoring room, and packaging area of the plant. This could be done by modifying existing equipment and/or installing new ventilation systems. An increase in air supplied to a given space may need to be offset with an increase in air exhausted from that space or other adjacent spaces as well. Until other improvements are made, consistently operate the existing roof-mounted exhaust fan between the roasters and grinders to help maintain negative pressure in the roasting and grinding areas, relative to the green bean storage area.

5. Consider installing local exhaust ventilation at the packaging machines where ground coffee is packaged if alpha-diketone concentrations remain elevated after other controls have been implemented.

\section{Administrative Controls}

Administrative controls are employer-dictated work practices and policies implemented to reduce or prevent hazardous exposures. Their effectiveness depends on employer commitment and employee acceptance. Regular monitoring and reinforcement are necessary to ensure that policies and procedures are followed consistently. 
1. Install a $\mathrm{CO}$ monitor and alarm near the main grinder, the packaging grinders, and the grinder in the flavoring room that can alert employees if and when $\mathrm{CO}$ levels exceed the NIOSH ceiling of $200 \mathrm{ppm}$. Employees should evacuate and move to an area of fresh air until the CO level drops below 200 ppm.

2. After engineering controls have been installed at the grinders and in the flavoring room, conduct personal air monitoring for diacetyl and 2,3-pentanedione on employees with primary duties in the production and administrative areas using OSHA Sampling Method 1012 for diacetyl [OSHA 2008] and OSHA Sampling Method 1016 for 2,3-pentanedione [OSHA 2010]. Because air levels of VOCs like diacetyl and 2,3-pentanedione may fluctuate from day to day based on production schedules, we recommend personal air sampling for diacetyl and 2,3-pentanedione over multiple days.

3. Whenever possible, employees should avoid spending time in the immediate area where coffee is being ground and/or ground coffee is being packaged.

4. Whenever possible, cover bins of roasted whole beans and ground coffee to aid in reducing the overall emission of alpha-diketones and other chemicals including $\mathrm{CO}$ and $\mathrm{CO}_{2}$, into the workplace. Specifically, ensure that whenever possible, hoppers filled with ground coffee are kept covered.

5. To reduce exposures to VOCs (including alpha-diketones) and CO, minimize production tasks that require employees to place their heads directly above or inside the roasted bean bins.

6. Continue to periodically clean the roaster's exhaust according to manufacturer instructions to remove chaff build up to reduce a fire hazard and to improve the efficiency, energy usage, and roaster performance.

7. Ensure employees understand potential hazards (e.g., diacetyl, 2,3-pentanedione, $\mathrm{CO}, \mathrm{CO}_{2}$, dust) in the workplace and how to protect themselves. OSHA's Hazard Communication Standard, also known as the "Right to Know Law" [29 CFR 1910.1200] requires that employees are informed and trained on potential work hazards and associated safe practices, procedures, and protective measures.

8. Ensure employees are educated to consider the risks of further exposure if they develop lower respiratory symptoms (e.g., cough, shortness of breath, wheezing) that are progressive and severe in degree. Employees should report new, persistent, or worsening respiratory symptoms to their personal healthcare providers and to a designated individual at this workplace. Employees with new, persistent, or worsening respiratory symptoms should share this report with their healthcare providers.

\section{Personal Protective Equipment}

The effectiveness of respiratory protection as personal protective equipment depends on avoiding breakdowns in implementation that can cause insufficient protection from respiratory exposures. Proper use of respiratory protection (respirators) requires a 
comprehensive respiratory protection program and a high level of employee and management involvement and commitment to assure that the right type of respirator is chosen for each hazard, respirators fit users, respirators are maintained in good working order, and respirators are worn when they are needed. Supporting programs such as training, change-out schedules, and medical assessment might be necessary. Respirators should not be the sole method for controlling hazardous inhalation exposures. Rather, respirators should be used until effective engineering and administrative controls are in place.

1. Until engineering and administrative controls are in place, respiratory protection for diacetyl and 2,3-pentanedione should continue to be used to reduce exposures to alpha-diketones. Require employees who operate grinders or flavor coffee in the packaging area to use respiratory protection with an assigned protection factor (APF) of 25 when performing flavoring and grinding tasks. Continue to use respiratory protection (with an APF of at least 25) in the flavoring room and near the main grinder.

2. If feasible, provide powered air-purifying respirators (PAPRs) with an APF of at least 25. PAPRs may be more comfortable for employees than the air-purifying respirators. Respirator should be worn at all times by all employees working in the flavoring room and grinding areas until additional measures (elimination, engineering controls, or administrative controls) can be applied to reduce the levels of diacetyl and 2,3-pentanedione below their respective NIOSH RELs and STELs. Respirators should be NIOSH-certified with NIOSH-certified organic vapor cartridges and particulate cartridges/filters.

Continue to implement the written respiratory protection program as required by the OSHA Respiratory Protection Standard (29 CFR 1910.134), including training, fit testing, maintenance, and use requirements for all employees who use respiratory protection.

a. Ensure N95 disposable filtering-face piece respirators are available for voluntary use for protection against green or roasted coffee dust exposure such as when emptying burlap bags of green beans, cleaning the roaster exhaust system of chaff, emptying the chaff containers, or cleaning the green bean storage area. N95 respirators should be available in various sizes, and each potential N95 user should receive a copy of Appendix D of the OSHA Respiratory Protection Standard (http://www.osha.gov/pls/oshaweb/owadisp.show document?p table=standards\&p_id=9784). Information about Appendix D and voluntary use of respirators can be found on the OSHA website at https://www.osha.gov/video/ respiratory protection/voluntaryuse transcript.html.

Please be aware that N95s are not protective against alpha-diketones (diacetyl, 2,3-pentanedione, or 2,3-hexanedione). In cases of dual exposure to dust and alpha-diketones, NIOSH-certified organic vapor cartridges (for the alphadiketones) and particulate cartridges/filters (for the dust) would be warranted. 


\section{Medical Monitoring}

The purpose of a medical monitoring program is to help ensure the health of employees who have workplace exposures (e.g., diacetyl, 2,3-pentanedione, green coffee beans/dust) known to pose risk for potentially serious health conditions such as asthma or obliterative bronchiolitis.

1. Institute a medical monitoring program for employees who work or assist in the production area. The medical monitoring should consist of evaluation with a questionnaire (to obtain health and work task information) and spirometry (to assess lung function) at baseline and at one year to monitor for respiratory symptoms and to establish employees' baseline in lung function and any abnormal decline in lung function in the first year. Subsequently, an annual questionnaire evaluation should occur to monitor for respiratory symptoms. New or worsening respiratory symptoms should prompt additional evaluation including spirometry. Details about spirometry and a medical monitoring program can be found in chapter 9 of the NIOSH Criteria Document [NIOSH 2016].

2. If an employee is identified as likely having lung disease from exposure to diacetyl or 2,3-pentanedione, it should be viewed as a sentinel event indicating that there was a breakdown in exposure controls and that there is potential risk for co-workers. Should this occur, the unanticipated source of exposure must be identified and brought under control. In addition, increased intensity of medical surveillance would be required for all employees performing similar job tasks or having similar or greater potential for exposure. The NIOSH Criteria Document provides detailed guidance on responses to such sentinel events [NIOSH 2016].

\section{Smoking Cessation Program}

In a workplace with risk of occupational lung disease, prevention of smoking-related lung disease is important and makes the detection of work-related adverse effects easier. We recommend implementing a smoking cessation program to assist employees to stop smoking. The Centers for Disease Control and Prevention offers tools and resources for setting up a smoking cessation program [CDC 2017b]. 


\section{Appendix A : Tables}

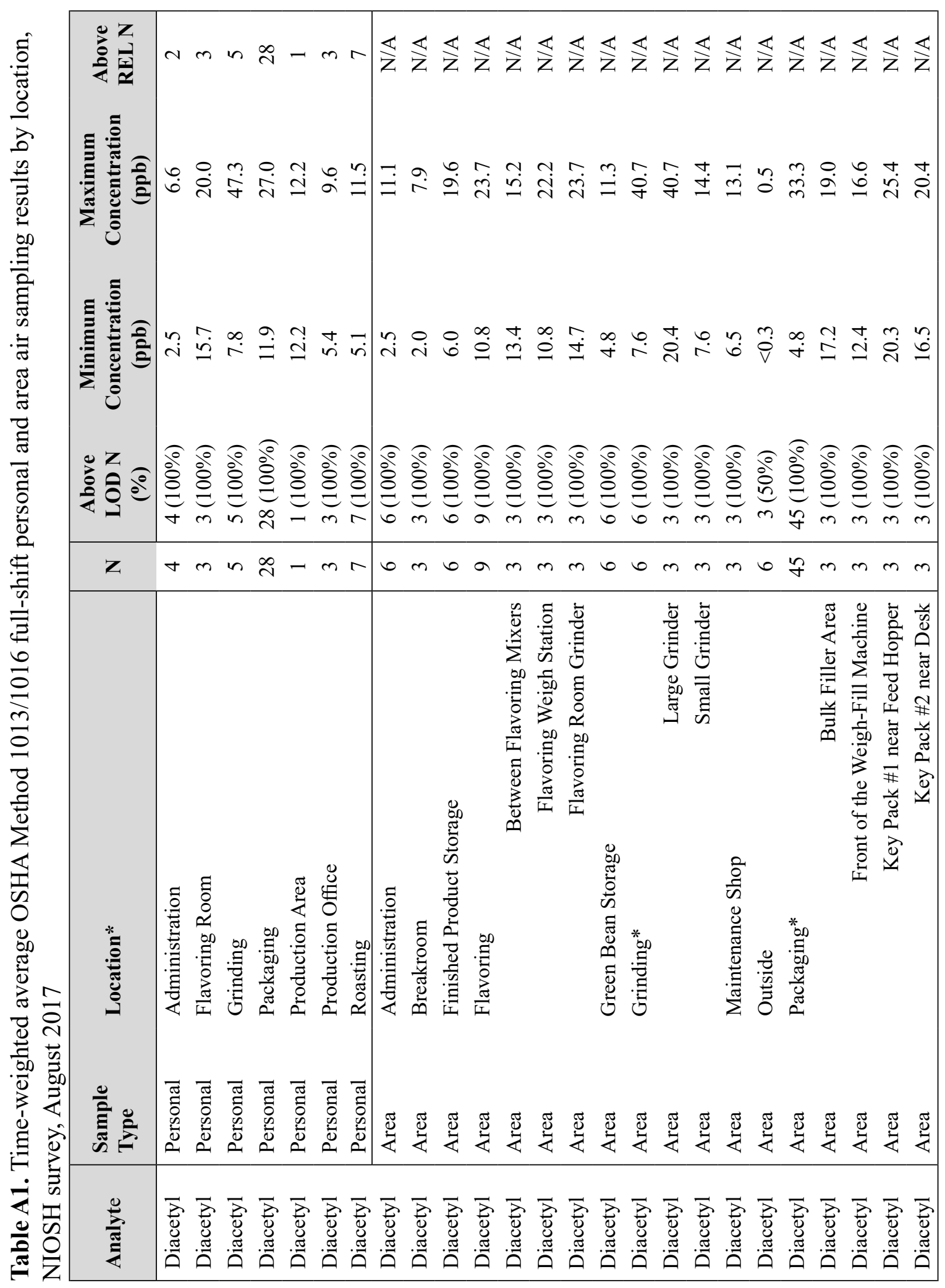




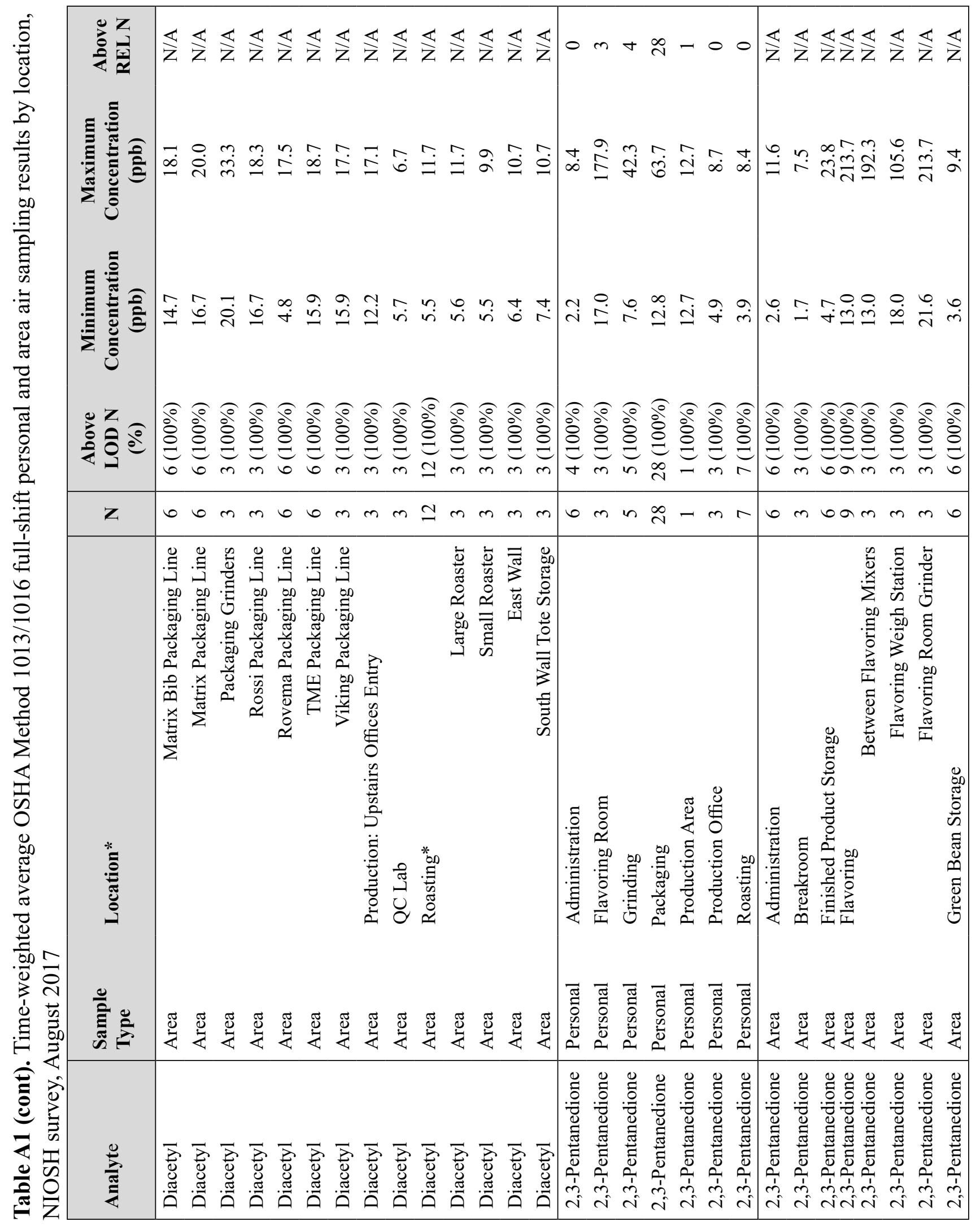




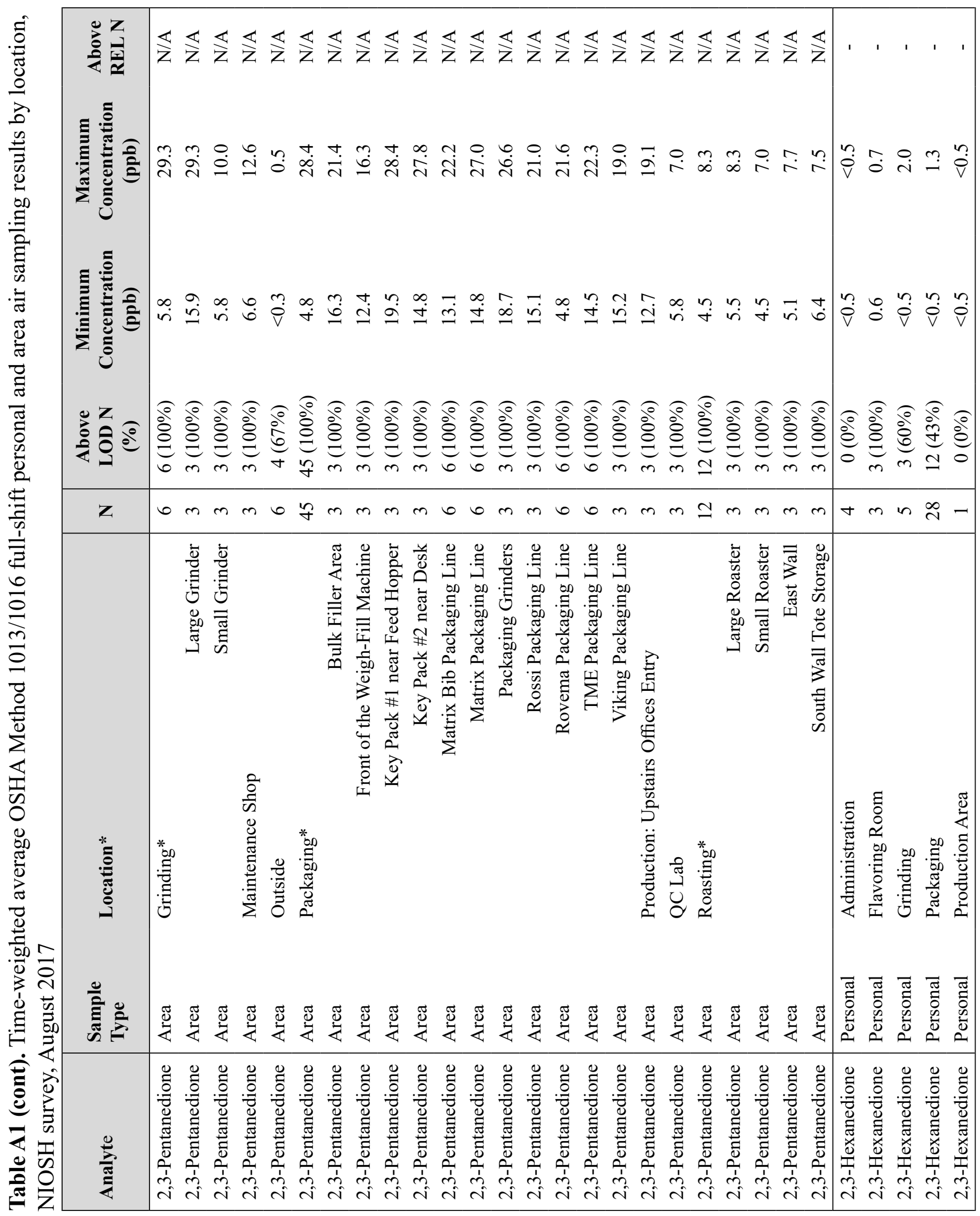




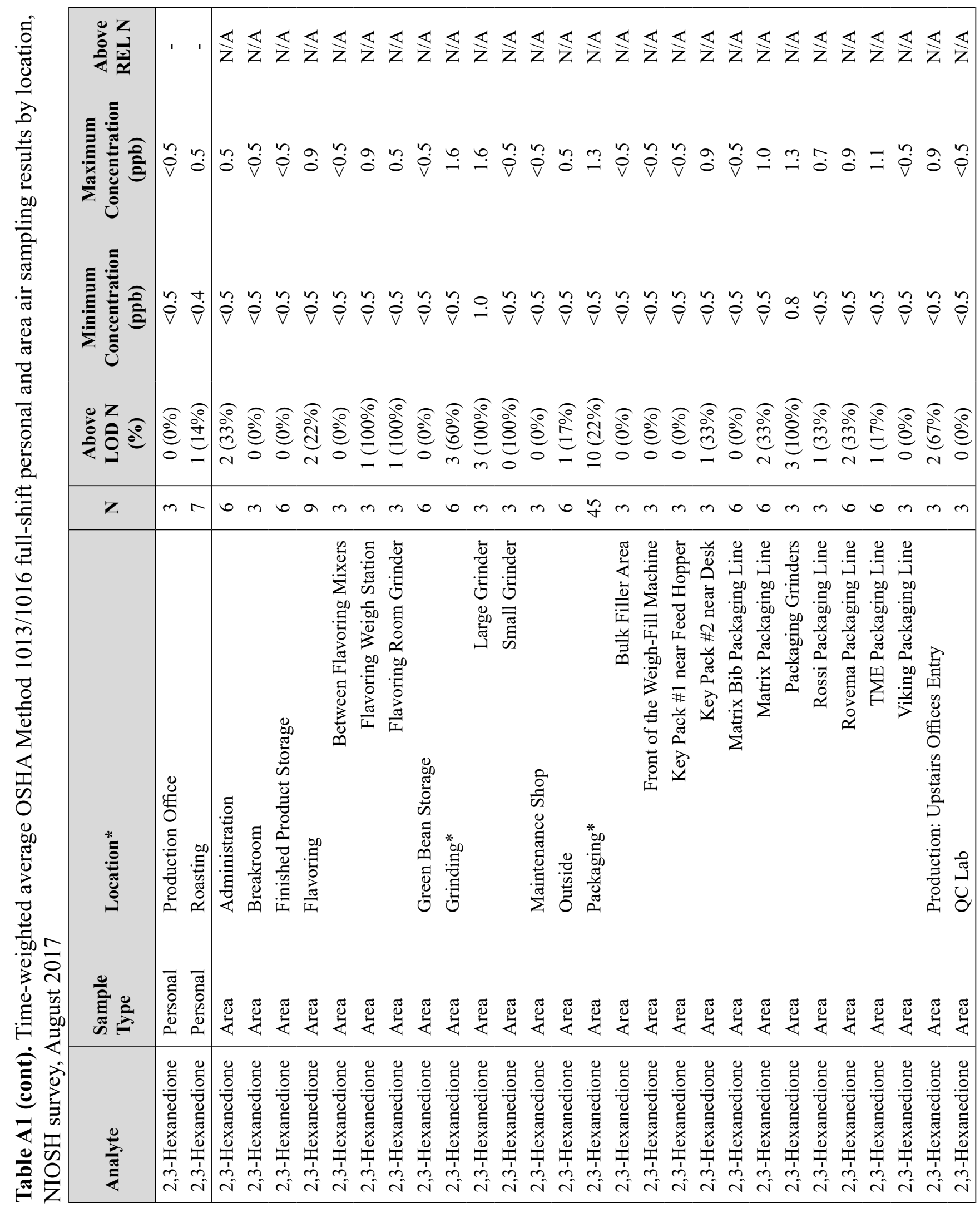







Table A2. Summary of short-term OSHA Method 1013/1016 personal air sampling results by task, NIOSH survey, August 2017

\begin{tabular}{|c|c|c|c|c|c|c|}
\hline Analyte & Task & $\mathbf{N}$ & $\begin{array}{l}\text { Above } \\
\text { LOD } \\
\text { N }(\%)\end{array}$ & $\begin{array}{c}\text { Minimum } \\
\text { Concentration } \\
(\mathbf{p p b})\end{array}$ & $\begin{array}{c}\text { Maximum } \\
\text { Concentration } \\
(p p b)\end{array}$ & $\begin{array}{c}\text { Mean (range) } \\
\text { Sample Duration } \\
\text { (minutes) }\end{array}$ \\
\hline Diacetyl & Cleaning Flavoring mixer & 1 & $1(100 \%)$ & 28.3 & 28.3 & 10 \\
\hline Diacetyl & Cleaning Packaging Machine & 1 & $1(100 \%)$ & 13.8 & 13.8 & 15 \\
\hline Diacetyl & Cleaning Roaster & 1 & $1(100 \%)$ & 3.4 & 3.4 & 7 \\
\hline Diacetyl & Cleaning grinders & 1 & $1(100 \%)$ & 18.7 & 18.7 & 15 \\
\hline Diacetyl & Flavor coffee & 6 & $5(83 \%)$ & $<0.9$ & 36.2 & $16(15-18)$ \\
\hline Diacetyl & Grind coffee beans (flavored and unflavored) & 7 & $6(86 \%)$ & 16.3 & 245.9 & $17(13-28)$ \\
\hline Diacetyl & Scooped whole roasted beans into a packaging machine & 1 & $1(100 \%)$ & 30.2 & 30.2 & 15 \\
\hline Diacetyl & Package coffee & 17 & $17(100 \%)$ & 14.1 & 38.1 & $15(15-17)$ \\
\hline Diacetyl & Roast coffee beans & 11 & $11(100 \%)$ & 0.7 & 17.3 & $16(11-20)$ \\
\hline 2,3-Pentanedione & Cleaning Flavoring mixer & 1 & $1(100 \%)$ & 18.9 & 18.9 & 10 \\
\hline 2,3-Pentanedione & Cleaning Packaging Machine & 1 & $1(100 \%)$ & 14.7 & 14.7 & 15 \\
\hline 2,3-Pentanedione & Cleaning Roaster & 1 & $1(100 \%)$ & 3.6 & 3.6 & 7 \\
\hline 2,3-Pentanedione & Cleaning grinders & 1 & $1(100 \%)$ & 20.3 & 20.3 & 15 \\
\hline 2,3-Pentanedione & Flavor coffee & 6 & $5(83 \%)$ & $<1.0$ & 723.5 & $16(15-18)$ \\
\hline 2,3-Pentanedione & Grind coffee beans (flavored and unflavored) & 7 & $6(86 \%)$ & 25.8 & 228.4 & $17(13-28)$ \\
\hline 2,3-Pentanedione & Scooped whole roasted beans into a packaging machine & 1 & $1(100 \%)$ & 23.6 & 23.6 & 15 \\
\hline 2,3-Pentanedione & Package coffee & 17 & $17(100 \%)$ & 12.5 & 68.0 & $15(15-17)$ \\
\hline 2,3-Pentanedione & Roast coffee beans & 11 & $10(91 \%)$ & $<0.8$ & 13.9 & $16(11-20)$ \\
\hline 2,3-Hexanedione & Cleaning Flavoring mixer & 1 & $0(0 \%)$ & $<2.1$ & $<2.1$ & 10 \\
\hline 2,3-Hexanedione & Cleaning Packaging Machine & 1 & $0(0 \%)$ & $<1.4$ & $<1.4$ & 15 \\
\hline 2,3-Hexanedione & Cleaning Roaster & 1 & $0(0 \%)$ & $<3.1$ & $<3.1$ & 7 \\
\hline 2,3-Hexanedione & Cleaning grinders & 1 & $0(0 \%)$ & $<1.4$ & $<1.4$ & 15 \\
\hline 2,3-Hexanedione & Flavor coffee & 6 & $0(0 \%)$ & $<1.1$ & $<1.4$ & $16(15-18)$ \\
\hline 2,3-Hexanedione & Grind coffee beans & 7 & $3(43 \%)$ & $<0.8$ & 12.2 & $17(13-28)$ \\
\hline 2,3-Hexanedione & Scooped whole roasted beans into a packaging machine & 1 & $0(0 \%)$ & $<1.4$ & $<1.4$ & 15 \\
\hline 2,3-Hexanedione & Package coffee & 17 & $1(6 \%)$ & $<1.2$ & 2.1 & $15(15-17)$ \\
\hline 2,3-Hexanedione & Roast coffee beans & 11 & $0(0 \%)$ & $<1.1$ & $<1.9$ & $16(11-20)$ \\
\hline
\end{tabular}

Note: OSHA=Occupational Safety and Health Administration; NIOSH=National Institute for Occupational Safety and Health; N=number of samples; Above LOD N (\%)=number and percentage of samples above limit of detection (LOD); < indicates below the LOD. 
Table A3. Instantaneous evacuated canister method* air sampling results by task, NIOSH survey, August 2017

\begin{tabular}{|c|c|c|c|}
\hline Task Description & $\begin{array}{l}\text { Diacetyl } \\
\text { (ppb) }\end{array}$ & $\begin{array}{c}\text { 2,3-Pentanedione } \\
\text { (ppb) }\end{array}$ & $\begin{array}{c}\text { 2,3-Hexanedione } \\
\text { (ppb) }\end{array}$ \\
\hline Adding HG flavoring to mixer with whole beans & 14.5 & 34.3 & 1.2 \\
\hline Adding TV flavoring to mixer with whole beans & 42.0 & 211 & $<6.9$ \\
\hline Adding HAZ and TV flavoring to whole bean coffee & 32.7 & 21.8 & $<1.1$ \\
\hline Adding TV flavoring to whole bean coffee & 33.3 & 28.3 & 4.0 \\
\hline Flavoring whole bean coffee with HAZ & 12.5 & 14.5 & 1.3 \\
\hline Flavoring whole bean coffee with HAZ and TV & 37.6 & 38.5 & 1.7 \\
\hline Scooping HAZ flavored coffee out of flavoring hopper & 18.7 & 7.6 & $<0.9$ \\
\hline Scooping TV flavored coffee out of flavoring hopper & 30.5 & 10.2 & $<0.7$ \\
\hline Standing at computer while flavoring with HAZ and TV & 24.0 & 13.2 & $<1.0$ \\
\hline Weighing liquid flavoring while hopper mixed coffee with flavoring & 14.8 & 13.1 & $<0.7$ \\
\hline Weighing TV liquid flavoring while hopper mixed coffee with flavoring & 509 & 9.3 & $<0.7$ \\
\hline Grinding 40 pounds of GEM flavored coffee & 77.7 & 178 & 2.2 \\
\hline Grinding 40 pounds of JMC-COMPANY 1 flavored coffee & $<0.4$ & 212 & $<0.7$ \\
\hline Grinding 40 pounds of TV flavored coffee & $<0.5$ & 33.2 & $<0.9$ \\
\hline Grinding 40 pounds of TV flavored coffee & 24.5 & 23.4 & 1.5 \\
\hline Grinding coffee at large grinder in roast room & 24.7 & 16.3 & $<1.1$ \\
\hline Grinding coffee at large grinder in roast room & 51.6 & 49.2 & $<0.9$ \\
\hline Grinding coffee at large grinder in roast room & 18.3 & 12.9 & 1.7 \\
\hline Grinding coffee at large grinder in roast room & 42.0 & 40.1 & $<0.7$ \\
\hline Grinding coffee at large grinder in roast room & 33.2 & 24.0 & $<9.5$ \\
\hline Grinding coffee at large grinder in roast room; Light Roast & 32.8 & 29.7 & 1.6 \\
\hline Pulling bean sample from large roaster while roasting & $<6.8$ & $<4.5$ & $<11.4$ \\
\hline Pulling bean sample from roaster while roasting & 2.7 & 1.7 & $<0.7$ \\
\hline Pulling bean sample from roaster while roasting & 6.7 & $<0.4$ & $<1.0$ \\
\hline Dumping roasted beans into cooling bin & $<4.5$ & $<3.0$ & $<7.5$ \\
\hline Dumping roasted beans into cooling bin; dark roast & 19.3 & 15.5 & 1.0 \\
\hline Dumping roasted beans into cooling bin & 4.3 & 2.7 & $<0.4$ \\
\hline Dumping roasted beans into cooling bin & 3.9 & 2.1 & $<0.7$ \\
\hline
\end{tabular}

Note: NIOSH=National Institute for Occupational Safety and Health; ppb=parts per billion; < indicates below the limit of detection.

*Sampling duration approximately 30 seconds; task-based air samples were collected by placing the inlet of the canister sampler in the employee's personal breathing zone as he/she performed work task. 


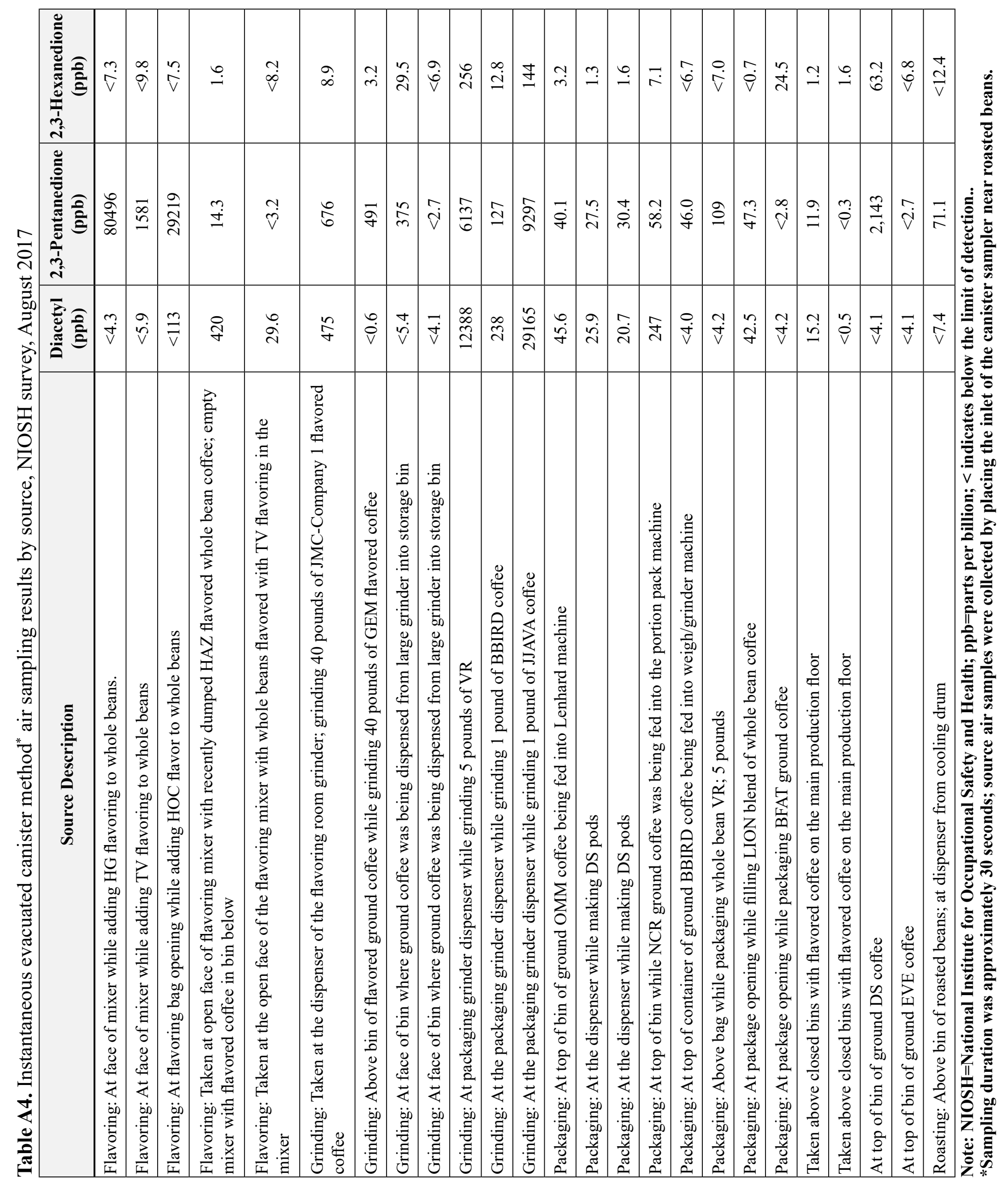


Table A5. Headspace analysis results for bulk samples of liquid flavorings,

NIOSH survey, August 2017

\begin{tabular}{|l|l|ccc|}
\hline Sample Type & Bulk Sample Description & $\begin{array}{c}\text { Diacetyl } \\
\text { (ppb) }\end{array}$ & $\begin{array}{c}\text { 2,3-Pentanedione } \\
\text { (ppb) }\end{array}$ & $\begin{array}{c}\text { 2,3-Hexanedione } \\
\text { (ppb) }\end{array}$ \\
\hline Flavoring & AMAR & 2,352 & $<118$ & $<210$ \\
Flavoring & TM & $<89$ & $<118$ & $<210$ \\
Flavoring & BR & $<89$ & $<118$ & $<210$ \\
Flavoring & CARM & 16,590 & $<118$ & $<210$ \\
Flavoring & PERX & $<89$ & $<118$ & $<210$ \\
Flavoring & DUT & $<89$ & $<118$ & $<210$ \\
Flavoring & JMC-Company 1 & $<89$ & 24,177 & $<210$ \\
Flavoring & JI-Company 2 & 297 & $<118$ & $<210$ \\
Flavoring & HAZ & 1,468 & $<118$ & $<210$ \\
Flavoring & HOC & 3,038 & 92,637 & $<210$ \\
Flavoring & MAC & 1,809 & $<118$ & $<210$ \\
Flavoring & PEP & 162 & $<118$ & $<118$ \\
Flavoring & VAN & 3,004 & $<10$ \\
\hline
\end{tabular}

Note: NIOSH=National Institute for Occupational Safety and Health; $\mathbf{p p b}=$ parts per billion.

Table A6. Summary of continuous area air monitoring results for carbon dioxide, carbon monoxide, temperature, and total volatile organic compounds, NIOSH industrial hygiene survey, August 2017

\begin{tabular}{|c|c|c|c|c|}
\hline Location, Day of Survey & $\begin{array}{c}\mathrm{CO}_{2}(\mathrm{ppm}) \\
\text { Mean (Range) }\end{array}$ & $\begin{array}{c}\text { CO (ppm) } \\
\text { Mean (Range) }\end{array}$ & $\begin{array}{c}\text { Temperature }\left({ }^{\circ} \mathbf{F}\right) \\
\text { Mean (Range) }\end{array}$ & $\begin{array}{c}\text { Total VOC (ppb) } \\
\text { Mean (Range) }\end{array}$ \\
\hline Flavoring Room: Grinder, day 1 & $\begin{array}{c}487 \\
(401-1272) \\
\end{array}$ & $\begin{array}{c}4.6 \\
(0.9-68.4) \\
\end{array}$ & $\begin{array}{c}76.4 \\
(73.4-80.1) \\
\end{array}$ & $\begin{array}{c}1,600 \\
(20-20,000)\end{array}$ \\
\hline Flavoring Room: Grinder, day 3 & $\begin{array}{c}475 \\
(393-840)\end{array}$ & $\begin{array}{c}5 \\
(0.7-101.7)\end{array}$ & $\begin{array}{c}77 \\
(74.3-81.3)\end{array}$ & $\begin{array}{c}1,536 \\
(<1-13,050)\end{array}$ \\
\hline Packaging: Grinders, day 1 & $\begin{array}{c}532 \\
(473-1,259)\end{array}$ & $\begin{array}{c}13.4 \\
(2.5-259.7)\end{array}$ & $\begin{array}{c}77.1 \\
(72.5-80.9)\end{array}$ & $\begin{array}{c}322 \\
(57-7,199)\end{array}$ \\
\hline Packaging: Grinders, day 2 & $\begin{array}{c}575 \\
(514-1,496) \\
\end{array}$ & $\begin{array}{c}11.2 \\
(3.0-369.7)\end{array}$ & $\begin{array}{c}75.4 \\
(70.3-81.1) \\
\end{array}$ & $\begin{array}{c}399 \\
(16-13,980) \\
\end{array}$ \\
\hline Packaging: Weigh Fill Machine, day 2 & - & - & - & $\begin{array}{c}1,252 \\
(75-4382)\end{array}$ \\
\hline Packaging: Key Pack \#1, day 3 & $\begin{array}{c}499 \\
(453-676) \\
\end{array}$ & $\begin{array}{c}4.6 \\
(3.1-10) \\
\end{array}$ & $\begin{array}{c}76.7 \\
(72.9-80.1) \\
\end{array}$ & $\begin{array}{c}344 \\
(<1-5,235)\end{array}$ \\
\hline Roast Room: Large Grinder, day 2 & $\begin{array}{c}479 \\
(336-1174) \\
\end{array}$ & $\begin{array}{c}17.4 \\
(0.9-170.5)\end{array}$ & $\begin{array}{c}78.3 \\
(70-86.9)\end{array}$ & $\begin{array}{c}600 \\
(<1-5,792)\end{array}$ \\
\hline Roast Room: Large Roaster, day 2 & $\begin{array}{c}448 \\
(397-824)\end{array}$ & $\begin{array}{c}3.3 \\
(<0.1-12.4)\end{array}$ & $\begin{array}{c}80.1 \\
(69.1-88.9)\end{array}$ & - \\
\hline
\end{tabular}

Note: $\mathrm{NIOSH}=$ National Institute for Occupational Safety and Health; $\mathrm{CO}_{2}=$ carbon dioxide; $\mathrm{CO}=$ carbon monoxide; ppm=parts per million; ${ }^{\circ} \mathrm{F}=$ degrees Fahrenheit; $\mathrm{VOC}=$ volatile organic compounds; "-"indicates the measurement was not recorded. 
Table A7. Summary of continuous personal air measurements for carbon monoxide, NIOSH industrial hygiene survey, August 2017

\begin{tabular}{|c|c|c|}
\hline Job Title & Work Area & $\begin{array}{c}\text { CO (ppm) } \\
\text { Mean (range) }\end{array}$ \\
\hline Grinder Operator & Large Grinder in Roast Room & $\begin{array}{c}5.8 \\
(0-294)\end{array}$ \\
\hline Grinder Operator & Large Grinder in Roast Room & $\begin{array}{c}7.4 \\
(0-233)\end{array}$ \\
\hline Grinder Operator & Large Grinder in Roast Room & $\begin{array}{c}10.9 \\
(0-769)\end{array}$ \\
\hline Flavoring Room Attendant & Flavoring Room & $\begin{array}{c}5.9 \\
(0-270) \\
\end{array}$ \\
\hline Flavoring Room Attendant & Flavoring Room & $\begin{array}{c}5.6 \\
(0-208)\end{array}$ \\
\hline Flavoring Room Attendant & Flavoring Room & $\begin{array}{c}5.3 \\
(0-99)\end{array}$ \\
\hline Flavoring Room Assistant & Wash Area in Roast Room & $\begin{array}{c}2.8 \\
(0-10)\end{array}$ \\
\hline Roaster Operator & Big Roaster & $\begin{array}{c}2.5 \\
(0-59)\end{array}$ \\
\hline Roaster Operator & Big Roaster & $\begin{array}{c}2.4 \\
(0-35)\end{array}$ \\
\hline Roaster Operator & Big Roaster & $\begin{array}{c}1.9 \\
(0-17) \\
\end{array}$ \\
\hline Roaster Operator & Small Roaster & $\begin{array}{c}1.3 \\
(0-5)\end{array}$ \\
\hline Roaster Operator & Small Roaster & $\begin{array}{c}1.9 \\
(0-8)\end{array}$ \\
\hline Roaster Operator & Small Roaster & $\begin{array}{c}1.0 \\
(0-6)\end{array}$ \\
\hline
\end{tabular}

Note: $\mathrm{NIOSH}=$ National Institute for Occupational Safety and Health; $\mathrm{CO}=$ carbon monoxide; $\mathrm{ppm}=$ parts per million; < indicates below the limit of detection for the instrument used to detect carbon monoxide. 
Table A8. Prevalence of reported symptoms, NIOSH medical survey, August 2017

\begin{tabular}{|c|c|c|}
\hline Symptom & $\begin{array}{c}\text { Experienced in the last } 12 \text { months } \\
\mathrm{N}=33 \\
\text { Number }(\%)\end{array}$ & $\begin{array}{l}\text { Experienced in the last } 4 \text { weeks } \\
\qquad \begin{array}{c}\mathrm{N}=33 \\
\text { Number }(\%)\end{array}\end{array}$ \\
\hline Nose symptoms* & $14(42 \%)$ & $9(27 \%)$ \\
\hline Eye symptoms $\dagger$ & $13(39 \%)$ & $10(30 \%)$ \\
\hline Sinusitis or sinus problems & $6(18 \%)$ & $3(9 \%)$ \\
\hline Problem with ability to smell & $3(9 \%)$ & - \\
\hline Phlegm on most days for 3 months & $7(21 \%)$ & - \\
\hline $\begin{array}{l}\text { Lower respiratory symptoms (reported at least } \\
\text { one of the following) }\end{array}$ & $17(52 \%)$ & $10(30 \%)$ \\
\hline Chest wheezing or whistling & $10(30 \%)$ & $6(18 \%)$ \\
\hline Usual cough & $7(21 \%)$ & $5(15 \%)$ \\
\hline SOB on level ground or walking up a slight a hill & $8(24 \%)$ & - \\
\hline Breathing trouble & $8(24 \%)$ & $5(15 \%)$ \\
\hline Awoke with chest tightness & $2(6 \%)$ & $1(3 \%)$ \\
\hline Asthma attack & $6(18 \%)$ & $2(6 \%)$ \\
\hline Awoke with shortness of breath & $3(9 \%)$ & $1(3 \%)$ \\
\hline $\begin{array}{l}\text { Systemic symptoms (reported at least one of the } \\
\text { following) }\end{array}$ & $12(36 \%)$ & $8(24 \%)$ \\
\hline Flu-like achiness or achy joints & $10(30 \%)$ & $4(12 \%)$ \\
\hline Fever or chills & $6(18 \%)$ & $3(9 \%)$ \\
\hline Unusual tiredness or fatigue & $7(21 \%)$ & $5(15 \%)$ \\
\hline
\end{tabular}

Note: $\mathrm{N}=$ number of participants; $\mathrm{SOB}=$ shortness of breath; "“_"= A four week question was not asked for the symptom.

*Nose symptoms includes one or both of the following: 1) stuffy, itchy, or runny nose or 2) stinging, burning nose.

$†$ Eye symptoms includes one or both of the following: 1) watery, itchy eyes or 2) stinging, burning eyes.

$\$$ This question did not specifically ask about a cough within the past 12 months; participants were asked, "Do you usually have a cough?" If the participants answered yes to that question, they were then asked, "Have you had a cough at any time in the last 4 weeks?" 
Table A9. Adjusted* comparisons of symptoms and self-reported physician diagnosis among NIOSH medical survey participants $(\mathrm{N}=33)$ to U.S. adult population August 2017

\begin{tabular}{|l|c|c|c|c|}
\hline \multicolumn{1}{|c|}{ Health condition } & $\begin{array}{c}\text { Comparative } \\
\text { population } \dagger\end{array}$ & $\begin{array}{c}\text { Observed } \\
\text { Number }\end{array}$ & $\begin{array}{c}\text { Expected } \\
\text { Number }\end{array}$ & $\begin{array}{c}\text { SMR } \\
((95 \% \text { CI }) \ddagger\end{array}$ \\
\hline Watery, itchy eyes last 12 months & NHANES III & 13 & 12.4 & $1.0(0.6-1.8)$ \\
\hline Stuffy, itchy, or runny nose last 12 months & NHANES III & 14 & 16.7 & $0.8(0.5-1.4)$ \\
\hline Sinus problems last 12 months & NHANES III & 6 & 11.1 & $0.5(0.2-1.2)$ \\
\hline Phlegm 3 consecutive month or more & NHANES III & 7 & 2.8 & $2.5(1.2-5.1)$ \\
\hline Wheeze last 12 months & NHANES 2007-2012 & 10 & 5.9 & $1.7(0.9-3.1)$ \\
\hline Shortness of breath on exertion & NHANES III & 8 & 7.3 & $1.1(0.6-2.1)$ \\
\hline Cough 3 consecutive months or more & NHANES III & 3 & 3.2 & $1.0(0.3-2.8)$ \\
\hline Ever asthma (physician-diagnosed) & NHANES 2007-2012 & 8 & 2.6 & $3.1(1.6-6.1)$ \\
\hline Current asthma (physician-diagnosed) $\beta$ & NHANES 2007-2012 & 7 & 1.7 & $4.1(2.0-8.4)$ \\
\hline
\end{tabular}

Note: NHANES=National Health and Nutrition Examination Survey; SMR= standardized morbidity ratio.

*Adjusted for sex, race/ethnicity, age, and smoking categories.

$\dagger$ We used the most recent NHANES survey available for each comparison.

$\$ 95 \%$ confidence intervals (CIs) that exclude one are statistically significantly different from comparison with US adult population and are shown in bold.

BOf the seven participants with current asthma, five reported being diagnosed prior to employment at the coffee roasting and packaging facility; two reported being diagnosed after employment at the coffee facility. 


\section{References}

ACGIH (American Conference of Governmental Industrial Hygienist) [2018a]. 2017 TLVs ${ }^{\circledR}$ and BEIs ${ }^{\circledR}$ : Threshold limit values for chemical substances and physical agents and biological exposure indices. Cincinnati, $\mathrm{OH}$ : American Conference of Governmental Industrial Hygienists.

ACGIH [2018b]. Chemicals Substances and Other Issues Under Study (TLV®-CS) [http://www.acgih.org/tlv-bei-guidelines/documentation-publications-and-data/under-studylist/chemical-substances-and-other-issues-under-study-tlv]. Date accessed: September 2018.

Akiyama M, Murakami K, Ohtani N, Iwatsuki K, Sotoyama K, Wada A, Tokuno K, Iwabuchi $\mathrm{H}$, Tanaka K [2003]. Analysis of volatile compounds released during the grinding of roasted coffee beans using solid-phase microextraction. J Agric Food Chem 51(7):1961-1969.

Akpinar-Elci M, Travis WD, Lynch DA, Kreiss K [2004]. Bronchiolitis obliterans syndrome in popcorn production plant workers. Eur Respir J 24(2):298-302.

Anderson BA, Shimoni E, Liardon R, Labuza P [2003]. The diffusion kinetics of carbon dioxide in fresh roasted and ground coffee. J Food Eng 59:71-78.

Bailey RL, Cox-Ganser JM, Duling MG, LeBouf RF, Martin SB Jr, Bledsoe TA, Green BJ, Kreiss K [2015]. Respiratory morbidity in a coffee processing workplace with sentinel obliterative bronchiolitis cases. Am J Ind Med 58(12):1235-1245.

Berger KI, Reibman J, Oppenheimer BW, Vlahos I, Harrison D, Goldring RM [2013]. Lessons from the World Trade Center disaster: airway disease presenting as restrictive dysfunction. Chest 144(1):249-257.

Burney PGJ, Chinn S [1987]. Developing a new questionnaire for measuring the prevalence and distribution of asthma. Chest 91(6 Suppl):79S-83S.

Burney PG, Laitinen LA, Perdrizet S, Huckauf H, Tattersfield AE, Chinn S, Poisson N, Heeren A, Britton JR, Jones T [1989]. Validity and repeatability of the IUATLD (1984) Bronchial symptoms questionnaire: an international comparison. Eur Respir J 2(10):940-945.

Burney PGJ, Luczynska C, Chinn S, Jarvis D [1994]. The European community respiratory health survey. Eur Respir J 7(5):954-960.

CDC (Centers for Disease Control and Prevention) [1996]. Third National Health and Nutrition Examination Survey, 1988-1994, NHANES III Examination Data File [CDROM]. Hyattsville, Maryland: U.S. Department of Health and Human Services, Centers for Disease Control and Prevention. (Public use data file documentation No. 76300.) 
CDC [2013a]. Carbon monoxide [https://www.cdc.gov/niosh/topics/co-comp/default.html]. Date accessed: September 2018.

CDC [2013b]. Obliterative bronchiolitis in workers in a coffee-processing facility-Texas, 2008-2012. Morb Mortal Wkly Rep 62(16):305-307.

CDC [2017a]. National Center for Health Statistics. National Health and Nutrition Examination Survey Data. Hyattsville, MD: U.S. Department of Health and Human Services, Centers for Disease Control and Prevention, [2007-2012] Available at: https://wwwn.cdc. gov/nchs/nhanes/default.aspx. Accessed: September 2018.

CDC [2017b]. Smoking \& tobacco use: quit smoking [https://www.cdc.gov/tobacco/stateandcommunity/tobacco control_programs/index.htm]. Date accessed: September 2018.

CFR. Code of Federal Regulations. Washington, DC: U.S. Government Printing Office, Office of the Federal Register.

Daglia M, Papetti A, Aceti C, Sordelli B, Spini V, Gazzani G [2007]. Isolation and determination of $\alpha$-dicarbonyl compounds by RP-HPLC-DAD in green and roasted coffee. $J$ Agric and Food Chem 55(22):8877-8882.

Day G, LeBouf R, Grote A, Pendergrass S, Cummings K, Kreiss K, and Kullman G [2011]. Identification and measurement of diacetyl substitutes in dry bakery mix production. J Occ Env Hygiene 8(2):93-103.

de Assumpção MS, Gonçalves RM, Martins R, Bobbio TG, Schivinski CI [2016]. Reference equations for impulse oscillometry system parameters in healthy Brazilian children and adolescents. Respir Care 61(8):1090-1099.

Desiraju K, Agrawal A [2016]. Impulse oscillometry: The state-of-art for lung function testing. Lung India 33(4):410-416.

Duling MG, LeBouf RF, Cox-Ganser JM, Kreiss K, Martin SB Jr, Bailey RL [2016]. Environmental characterization of a coffee processing workplace with obliterative bronchiolitis in former workers. J Occup Environ Hyg 13(10):770-781.

Dweik RA, Boggs PB, Erzurum SC, Irvin CG, Leigh MW, Lundberg JO, Olin AC, Plummer AL, Taylor DR; American Thoracic Society Committee on Interpretation of Exhaled Nitric Oxide Levels (FENO) for Clinical Applications [2011]. An official ATS clinical practice guideline: interpretation of exhaled nitric oxide levels (FENO) for clinical applications. Am J Respir Crit Care Med 184(5):602-615. 
EAACI Task Force on Occupational Rhinitis, Moscato G, Vandenplas O, Gerth Van Wijk R, Malo JL, Quirce S, Walusiak J, Castano R, De Groot H, Folletti I, Gautrin D, Yacoub MR, Perfetti L, Siracusa A [2008]. Occupational rhinitis. Allergy 63(8):969-980.

ECRHS (European Community Respiratory Health Survey) [2014]. Questionnaires, protocols and instructions [http://www.ecrhs.org/Quests.htm]. Date accessed: September 2018.

Ferris BG [1978]. Epidemiology standardization project. Am Rev Respir Dis 118(Suppl):1-53.

Figley KD, Rawling FF [1950] Castor bean: an industrial hazard as a contaminant of green coffee dust and used burlap bags. J Allergy 21:545-553.

Hawley B, Cox-Ganser JM, Cummings KJ [2017]. Carbon monoxide exposure in workplaces, including coffee processing facilities. J Respir Crit Care Med 196(8):1080-1081.

Hankinson JL, Odencrantz JR, Fedan KB [1999]. Spirometric reference values from a sample of the general U.S. population. Am J Respir Crit Care Med 159(1):179-187.

Henneberger PK, Redlich CA, Callahan DB, Harber P, Lemière C, Martin J, Tarlo SM, Vandenplas O, Torén K; ATS Ad Hoc Committee on Work-Exacerbated Asthma [2011]. An official American Thoracic Society statement: work-exacerbated asthma. Am J Respir Crit Care Med 184(3):368-378.

Hubbs AF, Cumpston AM, Goldsmith WT, Battelli LA, Kashon ML, Jackson MC, Frazer DG, Fedan JS, Goravanahally MP, Castranova V, Kreiss K, Willard PA, Friend S, SchweglerBerry D, Fluharty KL, Sriram K [2012]. Respiratory and olfactory cytotoxicity of inhaled 2,3-pentanedione in Sprague-Dawley rats. Am J Pathol 181(3):829-844.

Kanwal R, Kullman G, Piacitelli C, Boylstein R, Sahakian N, Martin S, Fedan K, Kreiss K [2006]. Evaluation of flavorings-related lung disease risk at six microwave popcorn plants. J Occup Environ Med. 48(2):149-57.

Karr RM, Davies RJ, Butcher BT, Lehrer SB, Wilson MR, Dharmarajan V, Salvaggio JE [1978]. Occupational asthma. J Allergy Clin Immunol 61(1):54-65.

Kim TJ, Materna BL, Prudhomme JC, Fedan KB, Enright PL, Sahakian NM, Windham GC, Kreiss K [2010]. Industry-wide medical surveillance of California flavor manufacturing workers: Cross-sectional results. Am J Ind Med 53(9):857-865.

King MS, Eisenberg R, Newman JH, Tolle JJ, Harrell FE Jr, Nian H, Ninan M, Lambright ES, Sheller JR, Johnson JE, Miller RF [2011]. Constrictive bronchiolitis in soldiers returning from Iraq and Afghanistan. N Engl J Med. 365(3):222-230. 
Komarow HD, Myles IA, Uzzaman A, Metcalfe DD [2011]. Impulse oscillometry in the evaluation of diseases of the airways in children. Ann Allergy Asthma Immunol 106(3):191199.

Kreiss K [2013]. Occupational causes of constrictive bronchiolitis. Curr Opin Allergy Clin Immunol 13(2):167-172.

Langford NJ [2005]. Carbon dioxide poisoning. Toxicol Rev 24(4):229-235.

LeBouf RF, Stefaniak AB, Virji, MA [2012]. Validation of evacuated canisters for sampling volatile organic compounds in healthcare settings. J Environ Monit 14(3):977-983.

LeBouf RF and Simmons M [2017]. Increased sensitivity of OSHA method analysis of diacetyl and 2,3-pentanedione in air. J Occup Environ Hyg 14(5):343-348.

Lee JY, Seo JH, Kim HY, Jung YH, Kwon JW, Kim BJ, Kim HB, Lee SY, Jang GC, Song DJ, Kim WK, Shim JY, Kim HJ, Shin YJ, Park JW, Cho SH, Lee JS, Hong SJ [2012]. Reference values of impulse oscillometry and its utility in the diagnosis of asthma in young Korean children. J Asthma 49(8):811-816.

Lehrer SB, Karr RM, Salvaggio JE [1978]. Extraction and analysis of coffee bean allergens. Clin Allergy 8(3):217-226.

Malmberg LP, Pelkonen A, Poussa T, Pohianpalo A, Haahtela T, Turpeinen M [2002]. Determinants of respiratory system input impedance and bronchodilator response in healthy Finnish preschool children. Clin Physiol Funct Imaging 22(1):64-71.

Miller MR, Hankinson J, Brusasco V, Burgos F, Casaburi R, Coates A, Crapo R, Enright P, van der Grinten CP, Gustafsson P, Jensen R, Johnson DC, MacIntyre N, McKay R, Navajas D, Pedersen OF, Pellegrino R, Viegi G, Wanger J, ATS/ERS Task Force [2005]. Standardisation of spirometry. Eur Respir J 26(2):319-338.

Morgan DL, Jokinen MP, Price HC, Gwinn WM, Palmer SM, Flake GP [2012]. Bronchial and bronchiolar fibrosis in rats exposed to 2,3-pentanedione vapors: implications for bronchiolitis obliterans in humans. Toxicol Pathol 40(3):448-465.

Morgan DL, Jokinen MP, Johnson CL, Price HC, Gwinn WM, Bousquet RW, Flake GP [2016]. Chemical reactivity and respiratory toxicity of the $\alpha$-diketone flavoring agents: 2,3-butanedione, 2,3-pentanedione, and 2,3-hexanedione. Toxicol Pathol 44(5):763-783.

Newbury W, Crockett A, Newbury J [2008]. A pilot study to evaluate Australian predictive equations for the impulse oscillometry system. Respirology 13(7):1070-1075.

Newton J [2002]. Carbon monoxide exposure from coffee roasting. Appl Occup Environ Hyg. 17(9):600-602. 
NIOSH [2016]. NIOSH pocket guide to chemical hazards. [http://www.cdc.gov/niosh/npg/]. Date accessed: September 2018.

NIOSH [2012]. Flavoring-related lung disease. Information for healthcare providers. Department of Health and Human Services, Centers for Disease Control and Prevention, DHHS (NIOSH) Publication No. 2012-148 (supersedes 2012-107) [http://www.cdc.gov/ niosh/docs/2012-148/]. Date accessed: August 2018.

NIOSH [2016]. Criteria for a recommended standard: occupational exposure to diacetyl and 2,3-pentanedione. U.S. Department of Health and Human Services, Centers for Disease Control and Prevention, National Institute for Occupational Safety and Health, DHHS (NIOSH) Publication No. 2016-111. [https://www.cdc.gov/niosh/docs/2016-111/]. Date accessed: September 2018.

Nishimura F, Abe S, Fukunaga T [2003]. Carbon monoxide poisoning from industrial coffee extraction. JAMA 290(3):334.

Oldenburg M, Bittner C, Baur X [2009]. Health risks due to coffee dust. Chest 136(2):536544.

Oppenheimer BW, Goldring RM, Herberg ME, Hofer IS, Reyfman PA, Liautaud S, Rom WN, Reibman J, Berger KI [2007]. Distal airway function in symptomatic subjects with normal spirometry following World Trade Center dust exposure. Chest 132(4):1275-1282.

OSHA (Occupational Safety and Health Administration) [1993]. Compliance and enforcement activities affected by the PELs decision. August 5, 1993 Memorandum. [https:// www.osha.gov/pls/oshaweb/owadisp.show document?p table=INTERPRETATIONS\&p $\underline{\mathrm{id}=21220]}$. Date accessed: September 2018.

OSHA [2003]. Enforcement policy for respiratory hazards not covered by OSHA permissible exposure limits. January 24, 2003 Memorandum. [https://www.osha.gov/pls/oshaweb/ owadisp.show document?p table=INTERPRETATIONS\&p id=24749]. Date accessed: September 2018.

OSHA [2008]. Sampling and analytical methods: Method 1013 - Acetoin and diacetyl [http:// www.osha.gov/dts/sltc/methods/validated/1013/1013.html]. Date accessed: September 2018.

OSHA [2010]. Sampling and analytical methods: Method 1016 - 2,3-pentanedione [http:// www.osha.gov/dts/sltc/methods/validated/1016/1016.html]. Date accessed: September 2018.

OSHA [2014]. OSHA Fact sheet: Do you have work-related asthma? A guide for you and your doctor. Washington, D.C.: U.S. Department of Labor, Occupational Safety and Health Administration [https://www.osha.gov/Publications/OSHA3707.pdf]. Date accessed:

September 2018. 
OSHA [2018]. Permissible exposure limits - annotated tables

[https://www.osha.gov/dsg/annotated-pels/index.html]. Date accessed: September 2018.

Park JH, Yoon JW, Shin YH, Jee HM, Wee YS, Chang SJ, Sim JH, Yum HY, Han MY [2011]. Reference values for respiratory system impedence using impulse oscillometry in healthy preschool children. Korean J Pediatr 54(2)64-68.

Pellegrino R, Viegi G, Brusasco V, Crapo RO, Burgos F, Casaburi R, Coates A, van der Grinten CP, Gustafsson P, Hankinson J, Jensen R, Johnson DC, MacIntyre N, McKay R, Miller MR, Navajas D, Pedersen OF, Wanger J [2005]. Interpretative strategies for lung function tests. Eur Respir J 26(5):948-968.

Raffel JB, Thompson J [2013]. Carbon monoxide from domestic coffee roasting: a case report. Ann Intern Med 159(11):795-796.

Rondón C, Campo P, Galindo L, Blanca-López N, Cassinello MS, Rodriguez-Bada JL, Torres MJ, Blanca M [2012]. Prevalence and clinical relevance of local allergic rhinitis. Allergy. 67(10):1282-1288.

Rondón C, Bogas G, Barrionuevo E, Blanca M, Torres MJ, Campo P [2017]. Nonallergic rhinitis and lower airway disease. Allergy 72(1):24-34.

Rose JJ, Wang L, Xu Q, McTiernan CF, Shiva S, Tejero J, Gladwin MT [2017]. Carbon monoxide poisoning: pathogenesis, management, and future directions of therapy. Am J Respir Crit Care Med 195(5):596-606.

Sahay S, Gera K, Bhargava SK, Shah A [2016]. Occurrence and impact of sinusitis in patients with asthma and/or allergic rhinitis. J Asthma 53(6):635-643.

Sakwari G, Mamuya SH, Bråtveit M, Moen BE [2013]. Respiratory symptoms, exhaled nitric oxide, and lung function among workers in Tanzanian coffee factories. J Occup Environ Med 55(5):544-551.

Schulz H, Flexeder C, Behr J, Heier M, Holle R, Huber RM, Jörres RA, Nowak D, Peters A, Wichmann HE, Heinrich J, Karrasch S; KORA Study Group [2013]. Reference values of impulse oscillometric lung function indices in adults of advanced age. PLoS One 8(5):e63366. doi: 10.1371/journal.pone.0063366.

Schulze J, Biedebach S, Christmann M, Herrmann E, Voss S, Zielen S [2016]. Impulse oscillometry as a predictor of asthma exacerbations in young children. Respiration 91(2):107114.

Shaaban R, Zureik M, Soussan D, Neukirch C, Heinrich J, Sunyer J, Wjst M, Cerveri I, Pin I, Bousquet J, Jarvis D, Burney PG, Neukirch F, Leynaert B [2008]. Rhinitis and onset of asthma: a longitudinal population-based study. Lancet. 372(9643):1049-1057. 
Shi Y, Aledia AS, Tatavoosian AV, Vijayalakshmi S, Galant SP, George SC [2012]. Relating small airways to asthma control by using impulse oscillometry in children.

Allergy Clin Immunol 129(3):671-678.

Smith HJ, Reinhold P, Goldman MD [2005]. Forced oscillation technique and impulse oscillometry. In: Gosselink R, Stam H, eds. European Respiratory Monograph 31: Lung Function Testing. Vol. 10. Wakefield, UK: European Respiratory Society Journals, pp. 72 105.

Smith HJ (Hans-Juergen.Smith@,CareFusion.com) [2015]. Questions about impulse oscillometry. Email of December 9, 2015, from Hans-Juergen Smith, CareFusion, to Rachel Bailey (feu2@cdc.gov), Respiratory Health Division, National Institute for Occupational Safety and Health, Centers for Disease Control and Prevention, Department of Health and Human Services.

Song TW, Kim KW, Kim ES, Park JW, Sohn MH, Kim KE [2008]. Utility of impulse oscillometry in young children with asthma. Pediatr Allergy Immunol 19(8):763-768.

Tarlo SM, Lemiere C [2014]. Occupational asthma. N Engl J Med 370:640-649.

Tarlo SM [2016]. Update on work-exacerbated asthma. Int J Occup Med Environ Health 29(3):369-374.

Thomas KE, Trigg CJ, Baxter PJ, Topping M, Lacey J, Crook B, Whitehead P, Bennett JB, Davies RJ [1991]. Factors relating to the development of respiratory symptoms in coffee process workers. Br J Ind Med 48(5):314-322.

Vogel J, Smidt U [1994] Impulse oscillometry. Analysis of lung mechanics in general practice and clinic, epidemiological and experimental research. $1^{\text {st }}$ ed. Frankfurt: PMIVerlagsgruppe.

Weinstein DJ, Hull JE, Ritchie BL, Hayes JA, Morris MJ [2016]. Exercise-associated excessive dynamic airway collapse in military personnel. Ann Am Thorac Soc 13(9):14761482.

Zuskin E, Valić F, Skurić Z [1979]. Respiratory function in coffee workers. Br J Ind Med 36(2):117-122.

Zuskin E, Kanceljak B, Skurić Z, Butković D [1985]. Bronchial reactivity in green coffee exposure. Br J Ind Med 42(6):415-420.

Zuskin E, Schachter EN, Kanceljak B, Witek TJ Jr, Fein E [1993]. Organic dust disease of airways. Int Arch Occup Environ Health 65(2):135-140. 
This page left intentionally blank 
Keywords: NAICS 311920 (Coffee roasting), Minnesota, diacetyl, 2,3-pentanedione, 2,3-hexanedione, coffee, carbon monoxide, carbon dioxide, volatile organic compounds (VOCs). 
The Health Hazard Evaluation Program investigates possible health hazards in the workplace under the authority of the Occupational Safety and Health Act of 1970 (29 U.S.C. $§$ 669(a) (6)). The Health Hazard Evaluation Program also provides, upon request, technical assistance to federal, state, and local agencies to investigate occupational health hazards and to prevent occupational disease or injury. Regulations guiding the Program can be found in Title 42, Code of Federal Regulations, Part 85; Requests for Health Hazard Evaluations (42 CPR Part 85).

\title{
Disclaimer
}

The recommendations in this report are made on the basis of the findings at the workplace evaluated and may not be applicable to other workplaces.

Mention of any company or product in this report does not constitute endorsement by the National Institute for Occupational Safety and Health (NIOSH).

Citations to Web sites external to NIOSH do not constitute NIOSH endorsement of the sponsoring organizations or their programs or products. NIOSH is not responsible for the content of these Web sites. All Web addresses referenced in this document were accessible as of the publication date.

\section{Acknowledgments}

\author{
Desktop Publisher: Tia McClelland \\ Data Analysis Support: Nicole Edwards, Kathleen Fedan, and Brian Tift \\ Laboratory Support: Dru Burns, Ryan LeBouf, Anand Ranpara \\ Site Visit Team Members: Mike Beaty, Randy Boylstein, Matthew Duling, Nicole Edwards, \\ Brie Hawley, Reid Harvey, Randy Nett, Alyson Johnson, Steve Martin, Nnenna Okoye, Laura \\ Reynolds, Marcia Stanton
}

\section{Availability of Report}

Copies of this report have been sent to the employer, employees, and union at the facility. The state and local health department and the Occupational Safety and Health Administration Regional Office have also received a copy. This report is not copyrighted and may be freely reproduced.

This report is available at http://www.cdc.gov/niosh/hhe/reports/pdfs/2017-0054-3327.pdf.

All other Health Hazard Evaluation Reports may be found at https://www2a.cdc.gov/hhe/ search.asp.

\section{Recommended citation for this report:}

NIOSH [2018]. Health hazard evaluation report: Evaluation of exposures and respiratory health at a coffee roasting and flavoring facility. By Hawley B, Reynolds LE, Harvey RR, Martin SB. Morgantown, WV: U.S. Department of Health and Human Services, Centers for Disease Control and Prevention, National Institute for Occupational Safety and Health, NIOSH HHE Report No. 2017-0054-3327. 
Delivering on the Nation's promise:

Safety and health at work for all people through research and prevention

To receive documents or other information about occupational safety and health topics, contact NIOSH

Telephone: 1-800-CDC-INFO (1-800-232-4636)

TTY: 1-888-232-6348

email: cdcinfo@cdc.gov

or visit the NIOSH website at http://www.cdc.gov/niosh

SAFER • HEALTHIER • PEOPLE ${ }^{\text {TM }}$ 